\title{
The Winners and Losers of Tax Reform: An Assessment under Financial Integration*
}

\author{
Ayşe Kabukçuoğlu ${ }^{\dagger}$ \\ Koç University
}

First draft: August 7, 2014

This draft: July 22, 2017

\begin{abstract}
I quantify the macroeconomic and redistributive effects of the unilateral elimination of the capital income tax in a two-country, heterogeneous-agent incomplete markets model with progressive labor income taxes. Home, by implementing the reform, induces government responses where labor income is taxed in Home, and mostly subsidized in Foreign. In addition, post-reform price dynamics reduce Home's wealth and suppress households' ability to do consumption smoothing, with negative effects on the majority - particularly on the poor. In turn, Foreign accumulates wealth, and price movements work particularly in favor of the poor. As a result, a large majority in Home prefers the status quo whereas Foreign supports the reform unanimously. These findings are robust to alternative scenarios where (i)
\end{abstract}

\footnotetext{
${ }^{*}$ I am indebted to my advisor, Andy Glover, for his guidance, encouragement, and support. I would also like to thank Olivier Coibion, Matthias Kehrig, Enrique Martínez-García, Jacek Rothert, Mark Wynne, Dean Corbae, Umut Dur, François Gourio, Refet Gürkaynak, Ayşe İmrohoroğlu, Aubhik Khan, Burhan Kuruş̧̧u, Sigrid Röhrs, Yongseok Shin, Yaz Terajima, Carlos Zarazaga, Jing Zhang, seminar participants at UT Austin, Federal Reserve Bank of Dallas, Bank of Canada, Koç University, Syracuse University, Bilkent University, Central Bank of Turkey, Econometric Society Meetings at Northwestern University and USC, and Midwest Macro Meeting at UC-Boulder, for many helpful comments. Part of the paper was completed while I was a summer intern at the Federal Reserve Bank of Dallas, whose support is greatly appreciated.

${ }^{\dagger}$ College of Administrative Sciences and Economics, Koç University. Rumelifeneri Yolu, Sariyer 34450, Istanbul, Turkey E-mail: akabukcuoglu@ku.edu.tr. Webpage: aysekabukcuoglu.weebly.com
} 
the borrowing constraints are relaxed, (ii) both countries jointly eliminate capital income taxes, (iii) foreign interest income is taxed, and (iv) Home capital income tax is reduced from $40 \%$ to $35 \%$.

JEL codes: E62, F41, D52, F68 Key words: Taxation, wealth inequality, heterogeneous agent-incomplete markets models, financial integration 


\section{Introduction}

Should the capital income tax be eliminated? Capital income tax cuts in general, such as the one introduced in the US by the Bush administration in 2003 and extended through 2012, have been the subject of intense debate in both academic and policy circles. ${ }^{1}$ Supporters of these tax reforms argue that they promote investment and output, and improve efficiency. Opponents, on the other hand, are concerned with the negative wealth distributional consequences of these reforms. They suggest that a capital tax cut primarily helps the rich.

Previous work studying the distributional effects of tax reforms has focused on closed economy-models, abstracting from countries' access to international financial markets. However, the globalization process has evolved over the past decades, deepening financial imbalances in the world, creating an environment where policy decisions can have different implications for countries and households. This motivates the current study in quantifying the desirability of capital income tax reforms under international capital mobility. In a two-country heterogenous agent-incomplete markets model calibrated to match the key macroeconomic and distributional aspects of the US and rest of the OECD, this paper explores how these model economies respond to the elimination of capital income taxes. In doing so, the paper also addresses how the gains and costs of the reform in a country are shared by both countries as well as the households of different income and wealth levels in these countries, which has also remained largely outside the focus of the literature.

Following Chamley (1986) and Judd (1985), a main finding in the Ramsey literature is that in the standard neoclassical growth model it is not optimal to tax capital in the long run. In a similar framework, a related policy prescription by Lucas (1990) was that if the highly distortionary capital income tax were to be replaced by a higher (and less distortionary) labor income tax in the US, households could enjoy significant welfare gains (a 1 percent increase in annual consumption) as the capital income tax cut stimulates investment, output and consumption. ${ }^{2}$ While the elimination of the capital income tax seems attractive in these closed economy models, it becomes even more attractive in a financially open economy since international borrowing amplifies the stimulus to invest-

\footnotetext{
${ }^{1}$ The Bush tax reform, known as the Jobs and Growth Tax Relief Reconciliation Act (JGTRRA), encompasses a cut in both capital gains and dividend taxes. This paper however, focuses only on capital gains taxes and aims to address a central question in this literature regarding the elimination of capital income taxes.

${ }^{2}$ As Lucas put it, the welfare gain is twice that of eliminating $10 \%$ inflation, and about 20 times that of eliminating the business cycle.
} 
ment and output and enables greater ability to do consumption smoothing during the transition. Mendoza and Tesar (1998) pointed out the importance of this channel, in a two-country neoclassical growth model. In such a setting, the elimination of the capital income tax leads to welfare gains to the US up to $33 \%$ more than in a closed economy model.

As one moves away from the neoclassical growth theory and considers an open economy under uninsured labor income risk and borrowing constraints, the welfare results change dramatically. In this more realistic environment, with flat-rate taxes on capital income and progressive taxes on labor income, the country that repeals its capital gains tax has an average permanent welfare loss of $7 \%$ of consumption. With only $4 \%$ of population that can potentially gain from it, the reform can be considered highly undesirable. The reform has positive spillover effects to the rest of the world: the average welfare gain is $40 \%$ and the whole population gains from the reform. Moreover, in a closed-economy version of the analysis which is also considered in this paper for comparison with the literature, the average welfare loss goes up to $9 \%$, while the benefits are shared by a larger number of households given by $13 \%$. Why is this so?

The key channels that determine the (un)desirability of the tax reform in this setting are (i) the dynamics of after-tax interest rates and labor income (ii) the cross-country and within-country redistribution of wealth (iii) the way governments meets the budget constraints (i.e. by issuing debt and/or adjusting average labor income taxation in the economy). By altering the amount of precautionary savings and the ability to do consumption smoothing, the reform has quantitatively different implications on households at different income and wealth levels and in different countries.

The model studied is a two-country version of the Aiyagari (1994a) model where these financially-integrated countries, Home and Foreign, are calibrated to represent the US and the rest of the OECD countries, respectively. The framework is related to the heterogeneous-agent incomplete markets models of Bewley (1986), İmrohoroğlu (1989), Huggett (1993), as well as Aiyagari (1994a) which is a one-sector neoclassical growth model with uninsurable idiosyncratic labor income risk and borrowing constraints. I enhance the model further by including government policy. ${ }^{3}$ In this setting, I conduct an experiment à la Lucas (1990), Mendoza and Tesar (1998), Domeij and Heathcote (2004), among others, by introducing a unilateral, unanticipated and permanent capital income tax cut

\footnotetext{
${ }^{3}$ See Aiyagari and McGrattan (1998), Domeij and Heathcote (2004), Röhrs and Winter (2011), and Azzimonti, de Fransisco and Quadrini (2012) with examples of government policy in a heterogeneous agent-incomplete markets framework.
} 
in the US. The consequences of the reform are evaluated taking into account both steady state gains and the transitional dynamics. In particular, households with various initial wealth and labor productivity levels are tracked over time after the reform takes place, and their welfare is compared to the status quo. The calibration of the benchmark model of financial openness is realistic in the sense that at the initial steady state equilibrium, some relevant aspects of the macroeconomy and asset holding distributions across different wealth groups match the data for the US and the OECD.

The main experiment conducted can be described as follows. Consider two countries, Home and Foreign, that are financially integrated. Home, which unilaterally eliminates the capital income tax of $39.7 \%$, accumulates physical capital and increases output, and can continue to do so by relying increasingly more on international borrowing as the world interest rate starts falling towards the reformed steady state. While external borrowing smooths out the transition path, it comes at the expense of a reduction in long-run consumption gains to service the debt. The government facing an unbalanced budget constraint has to adjust the average labor income taxation by taxing households at different levels of labor earnings. This adjustment takes place not only in Home, but also in Foreign where international capital flows and price movements affect households' incomes and therefore the Foreign government's tax revenues. In turn, the governments' need to adjust labor income taxes, in order to maintain fiscal solvency will affect the wealth distributions. In particular, the tax reform affects households depending on the composition of capital and labor earnings. The joint effect of these channels can only be determined with a quantitative exercise.

In many respects, the quantitative results between an open economy and an autarkic economy can be quite different. The capital accumulation in Home under financial integration is so large that the after-tax labor income of households goes up by $0.8 \%$ in Home between the two steady states, whereas in the closed economy version of the analysis there is a $2.1 \%$ decline. In turn, these dynamics in capital accumulation decrease (increase) the after tax returns to assets between the two steady states under financial integration (autarky). Therefore, poor households that rely predominantly on labor income will benefit mainly due to the increases in after-tax labor income in the open economy. In turn, households will also have lower returns to their asset holdings, which makes the reform less attractive for them, and especially for the rich. The quantitative results are such that a larger fraction of households suffers from net welfare losses under financial integration than autarky. On the other hand, Foreign residents enjoy large welfare gains. 
Foreign government can still raise tax revenues from capital income, and also benefits from sizable wealth transfers from Home towards the new steady state. This enables Foreign to provide subsidies, rather than impose taxes, on the labor income of majority of households. These transfers go up by $52 \%$ in the long run. Hence, despite the adverse interest rate dynamics, the increases in labor income bring large welfare gains that offset losses, for all households.

In a closely-related work, Domeij and Heathcote (2004) quantitatively showed that in an autarkic economy, given a highly concentrated wealth distribution as in the US, the elimination of the capital income tax would not be supported by the majority of the population. ${ }^{4}$ I argue that the unilateral elimination of the capital income tax in a utilitarian sense is not only much less desirable for Home, but also highly desirable for Foreign.

The aggregate welfare result after the elimination of the capital income tax, which is negative, is in line with the existing literature conducting similar experiments of capital taxation under incomplete asset markets characterized by uninsured idiosyncratic risk and borrowing constraints. Domeij and Heathcote (2004) studying an Aiyagari-type economy with flat-rate taxes find a negative result. Ábraham and Cárceles-Poveda (2009) report negative aggregate welfare results studying tax reforms with endogenous borrowing constraints.

Aiyagari (1995) suggests that for a closed economy and in the presence of precautionary savings motive, households accumulate too much capital so that taxing capital helps bring the capital stock to the efficient (i.e. the full insurance) level. Therefore, a positive capital income tax is optimal in the long run. İmrohoroğlu (1998) and Conesa, Kitao, and Krueger (2009) study tax reforms in life cycle models when households are uninsured against idiosyncratic labor income risk and face borrowing constraints. In these environments, replacing the capital income tax by a higher labor income tax imposes greater burden on agents when they are younger and liquidity constrained, reducing their ability to smooth consumption. They also quantitatively characterize the optimal capital tax rate and find that a positive long-run tax is optimal. On the other hand, Davila, Hong, Krusell, and Ríos-Rull (2012) study the notion of constrained efficiency, which considers the efficient allocations taking market incompleteness as given, in model economies with uninsurable idiosyncratic income risk. Their finding is that the capital stock in the decentralized

\footnotetext{
${ }^{4}$ Domeij and Heathcote (2004) abstract from progressive labor income taxes, while the current paper considers a model with labor income tax progressivity.
} 
economy is much too low compared to the constrained-efficient allocations. The policy implication for this result is that capital should be subsidized, and not taxed.

Neither efficiency nor constrained efficiency in open economies with incomplete markets have been studied before. Therefore, it is an open question what the optimal tax rate should be in this type of economies. The closed-economy literature suggests a wide range of values, which might vary based on model specifications and calibration. For these reasons and as an initial step, I consider $0 \%$ capital income tax rates in the benchmark experiment.

The results found in the main analysis appear to be robust under alternative scenarios as well. In particular, (i) going from $39.7 \%$ towards a $35 \%$ capital income tax as prescribed by Aiyagari (1994a), (ii) eliminating capital income taxes while foreign interest income is taxed, or (iii) eliminating capital income taxes under looser borrowing constraints yield the common result that a large majority in Home suffer welfare losses from the tax reform while Foreign residents support the reform unanimously.

In open economy models, domestic tax policy has been shown to have effects on other countries' tax policies. Mendoza and Tesar (1998, 2004), Mendoza, Tesar, and Zhang (2013) study global tax reforms in two-country neoclassical growth models. ${ }^{5}$ In Mendoza and Tesar (1998), where the model is calibrated to the US and Europe, the unilateral elimination of the capital income tax may become a beggar-thy-neighbor policy, with positive (negative) welfare effects to the reforming country (rest of the world). If both countries eliminate capital income taxes simultaneously, however, then both countries gain. Under the current framework this no longer holds: the unilaterally-implemented policy becomes rather a beggar-thyself policy, with favorable welfare consequences to the rest of the world. In turn, a joint decision to eliminate capital income taxes still remains undesirable for Home but desirable for Foreign.

Finally, this study is also related to two papers by Mendoza, Quadrini, and RíosRull (2007, 2009). In a two-country heterogeneous agents model, they depict how global financial imbalances have emerged as well as quantifying the welfare effects of financial integration (Mendoza, Quadrini, and Ríos-Rull, 2007)). The current framework is complementary to this strand of the literature in two dimensions. First, it explains how a capital income tax cut may deteriorate the US net foreign asset and current account imbalances. In this case, increasing the capital taxes, rather than decreasing them, may help reduce the

\footnotetext{
${ }^{5}$ Klein, Quadrini and Ríos-Rull (2005) and Quadrini (2005) analyze tax policy when governments conduct optimal fiscal policy without commitment under international mobility of capital.
} 
global financial imbalances. Second, the current paper gives an understanding of how tax policy may mitigate or exacerbate the negative redistributive consequences of financial globalization through wage and interest rate dynamics. Financial liberalization, alone, is an important channel in altering these dynamics and creating adverse redistributive consequences especially in financially less developed countries and for poor households. The current work, therefore, suggests a mechanism for policy-makers in shaping their tax policies in these countries.

I proceed with the model in the next section. In section 3, I discuss the long run equilibrium effects of a capital income tax cut and explain the numerical solution as well as the calibration strategy. Section 4 provides the results and section 5 concludes.

\section{The Model}

I introduce a two-country, heterogeneous agent-incomplete markets model. There are two financially integrated countries in the world economy, Home and Foreign. Foreign variables are denoted by an asterisk $\left(^{*}\right)$. For convenience, part of the model is presented for Home only and Foreign variables are introduced when needed.

\subsection{Households}

Each country is inhabited by a continuum of households which receive shocks to labor efficiency, $\varepsilon_{t} \in E$ which are i.i.d. across households and persistent over time. This is the only uncertainty in the model. Household choices in period $t$ are made after observing $\varepsilon_{t}$. A household receiving a shock $\varepsilon_{t}$ earns a labor income $\varepsilon_{t} n w_{t}$. The efficiency shock $\varepsilon_{t}$ evolves over time according to a $m$-state $(m<\infty)$ first-order Markov process defined with an $m \times m$ transition probability matrix $\Pi=\left[\pi_{i j}\right]$, where $\pi_{i j}=\operatorname{Pr}\left(\varepsilon_{t+1}=\varepsilon_{j} \mid \varepsilon_{t}=\varepsilon_{i}\right)$. All elements of $\Pi$ are non-negative and each row sums up to 1 . I denote the finite history of these shocks from date 0 up to date $t$ by $\varepsilon^{t}=\left\{\varepsilon_{0}, \ldots, \varepsilon_{t}\right\}$. To denote the probability distribution over $E$ at any period $t$, I use the vector $p_{t} \in \mathbb{R}^{m}$. Initial distribution is denoted by $p_{0}$ and the date- $t$ distribution is then given by $p_{t}=p_{0} \Pi^{t}$. $E$ has a unique ergodic set, no cyclically moving subsets and for any given $p_{0},\left\{p_{t}\right\}_{t=0}^{\infty}$ converges to the (unique) limit $p^{*}$. I start by assuming $p_{0}=p^{*}$, therefore the aggregate effective labor supply $N$ converges to a constant. 
Households maximize their expected life-time utility given by

$$
E_{0}\left[\sum_{t=0}^{\infty} \beta^{t} \log \left(c_{t}\right)\right]
$$

where $\beta \in(0,1)$ is the discount rate. The period utility function $U(\cdot)$ is strictly increasing, strictly concave and continuously differentiable. In each period, a household's consumption is denoted by $c_{t}$ and hours worked by $n$. Preferences and income shock processes are assumed to be the same for both countries. There is a single, composite consumption good, traded across countries.

Households face the following budget constraint taking as given the relative prices and tax rates at each period

$c_{t}+\underbrace{b_{t+1}+d_{t+1}+k_{t+1}}_{\equiv a_{t+1}} \leq \tau^{n}\left(\varepsilon_{t} n w_{t}\right)^{\psi}+\underbrace{\left[1+\left(r_{t}^{k}-\delta\right)\left(1-\tau^{k}\right)\right] k_{t}+\left[1+r_{t}^{d}\left(1-\tau^{k}\right)\right] d_{t}+\left(1+r_{t}\right) b_{t}}_{\equiv\left(1+r_{t}\right) a_{t}}$.

Household expenditures are given on the left-hand side of the budget constraint. Accordingly, they may purchase consumption goods $c_{t}$ and borrow or lend in the amount of their asset holdings, $a_{t+1}$. Specifically, households may invest in either 1-period, nonstate-contingent private bonds, $b_{t+1}$ which are traded internationally at an interest rate $r_{t}$, non-state-contingent public bonds $d_{t+1}$, which are traded only domestically at an interest rate $r_{t}^{d}$ or capital goods, $k_{t+1}$, that are also traded domestically. The right-hand side of the budget constraint includes factor and non-factor income of the household. Households' disposable labor income is given by $\tau^{n}\left(\varepsilon_{t} n w_{t}\right)^{\psi}$ where labor income is taxed progressively based on a two-parameter progressive labor income tax function as in Heathcote, Storesletten, and Violante (2014). More generally, the tax function is defined as $\tau(y)=y-\tau^{n} y^{\psi}$ where $y=\varepsilon n w$ denotes pre-tax labor earnings, $\psi$ captures the progressivity of tax system, with $\psi=1$ implying a flat-rate tax. The second parameter, $\tau^{n}$, determines the average taxation of labor income. A flat-rate, constant tax $\tau^{k} \in[0,1]$ is imposed on households' net return from physical capital and therefore physical capital has an after-tax return of $\left(r_{t}^{k}-\delta\right)\left(1-\tau^{k}\right)$ as well as the return on government bond holdings $r_{t}^{d}\left(1-\tau^{k}\right)$ Finally, private bond holdings yield an income equal to $\left(1+r_{t}\right) b_{t}$. 
Notice that optimal portfolio allocation implies

$$
r_{t}=r_{t}^{d}\left(1-\tau^{k}\right)=\left(r_{t}^{k}-\delta\right)\left(1-\tau^{k}\right)
$$

Hence, the international return on private bonds is equal to the net-of-tax return on government debt and net-of-tax return on physical capital in each period. Since the model assumes no aggregate shocks and the real one-period return from private and public debt are guaranteed (assuming that there is no default on private or public debt in any countries) all three assets are considered perfect substitutes. Therefore, we are able to state the household's problem without considering the portfolio composition of assets. The budget constraint can now be re-written as

$$
c_{t}+a_{t+1} \leq \tau^{n}\left(\varepsilon_{t} n w_{t}\right)^{\psi}+\left(1+r_{t}\right) a_{t} .
$$

In each period, individuals are able to borrow up to an exogenous limit, denoted by a. Therefore at any period $t$ :

$$
a_{t} \geq \underline{\text { a. }}
$$

The borrowing constraint is the same for all individuals in a country and also the same across countries. When households face a borrowing constraint, this implies that a household can have a long position in one type of asset while having a short position in another to the extent that the net asset position does not fall below the limit.

Define $\left(a_{t}, \varepsilon_{t}\right)$ as the state vector of the household at any $t$. Given the deterministic sequences of prices $\left\{w_{t}, r_{t}^{k}, r_{t}^{d}, r_{t}\right\}_{\tau=0}^{\infty}$, government policy $\left\{\tau, \tau^{k}\right\}$ and initial conditions $\left(a_{0}, \varepsilon_{0}\right)$, a household in Home maximizes (1), subject to (2) and (3). The household's optimization problem in Foreign can be defined similarly.

On a final note, in an equilibrium under financial integration and under the residence principle, it is needed to make this rather extreme assumption where capital and government bonds are only held by domestic residents so that cross-country differences in capital taxes prevail. If capital and/or government bonds were traded across countries, then no-arbitrage would imply that a household would pay the same tax on their domestic and foreign capital (or government bond) holdings as the after-tax returns would be equalized in an equilibrium under financial integration. This equilibrium with equal tax rates across countries would not be consistent with the observation that these tax rates may differ across countries. (See, for instance, Mendoza and Tesar (1998) for a similar discussion for a two-country neoclassical growth model.) 


\subsection{Production}

In Home (Foreign), aggregate output $Y_{t}\left(Y_{t}^{*}\right)$ is produced by a representative firm using aggregate capital $K_{t}\left(K_{t}^{*}\right)$, and aggregate labor $N\left(N^{*}\right)$, according to a constant returns to scale production function: ${ }^{6}$

$$
Y_{t}=F\left(K_{t}, N\right) \text { and } Y_{t}^{*}=F\left(K_{t}^{*}, N^{*}\right)
$$

Capital depreciates at the rate $\delta \in[0,1]$ in both countries. Households competitively supply physical capital to the firm in their respective countries at a real rental rate $r_{t}^{k}$ and $r_{t}^{k *}$, and labor (inelastically) at a real wage $w_{t}$ and $w_{t}^{*}$. Both factors are internationally immobile. Perfect competition in factor markets implies firms make zero profits in equilibrium.

\subsection{Government}

Governments finance their expenditures by issuing bonds and collecting taxes. The period$t$ real aggregate debt issued is given by, $D_{t+1}$ and $D_{t+1}^{*}$, respectively. The real one-period return to government debt is risk-free and equal to $r_{t}^{d}$ and $r_{t}^{d *}$. The fixed amount of real per capita government expenditures are denoted by, $G$ and $G^{*}$. The assumption that Home government debt (and similarly for Foreign) is only held by domestic residents - in contrast to private bonds that are traded internationally - enables us to have a well-defined solution for the aggregate amount of private bonds, $B_{t}$ and public bonds, $D_{t}$ since these assets are perfect substitutes. (Notice that at the household level, there is no well-defined portfolio allocation for $b_{t}, d_{t}$ or $k_{t}$.)

The governments collect progressive labor income taxes from households given by $\tau(\cdot)$ and $\tau^{*}(\cdot)$ which sum up to an aggregate amount denoted by, $T R_{t}$ and $T R_{t}^{*}$, respectively. In addition, the governments tax rental and interest income on equity and government bonds at rates $\tau^{k}$ and $\tau^{k *}$. The date- $t$ budget constraint for each government is as follows:

$$
\begin{gathered}
G+r_{t}^{d} D_{t}=D_{t+1}-D_{t}+T R_{t}+K_{t}\left(r_{t}^{k}-\delta\right) \tau^{k}+D_{t} r_{t}^{d} \tau^{k} \\
G^{*}+r_{t}^{d *} D_{t}^{*}=D_{t+1}^{*}-D_{t}^{*}+T R_{t}^{*}+K_{t}^{*}\left(r_{t}^{k *}-\delta\right) \tau^{k *}+D_{t}^{*} r_{t}^{d *} \tau^{k *},
\end{gathered}
$$

$D_{0}$ and $D_{0}^{*}$ given.

\footnotetext{
${ }^{6}$ Following the literature, all aggregate variables are denoted by capital letters.
} 


\subsection{Equilibrium}

Let $A$ be the set of the possible values of household wealth (set of endogenous states). Since households are allowed to borrow up to an exogenous (possibly negative) limit, a $A=[\underline{a}, \infty]$. Let $(A, \mathcal{A})$ and $(E, \mathcal{E})$ be measurable spaces where $\mathcal{A}$ denotes the Borel set that are subsets of $A$ and $\mathcal{E}$ is the set of all subsets of $E$. Let $(S, \mathcal{S})=(A \times E, \mathcal{A} \times \mathcal{E})$ be the product space and $S$ is the set of all possible household states. The solution to the household's problem provides the decision rules for consumption, $c_{t}=h_{c}\left(a_{t}, \varepsilon_{t}\right)$ and asset holdings, $a_{t+1}=h_{a}\left(a_{t}, \varepsilon_{t}\right)$ given the initial conditions $\left(a_{0}, \varepsilon_{0}\right)$ and if the history of idiosyncratic shocks up to $t$ is $\varepsilon^{t}$. These rules determine the evolution of the distribution of agents over $\left(a_{t}, \varepsilon_{t}\right)$. I define the joint distribution of households across both household wealth and labor efficiency at date $t$ by $\Gamma_{t}\left(a_{t}, \varepsilon_{t}\right)$. A household with the state $\left(a_{t}, \varepsilon_{t}\right)$ will have a state vector lying in $A_{t+1} \times E_{t+1}$ next period, given this period's distribution $\Gamma_{t}\left(a_{t}, \varepsilon_{t}\right)$ and the decision rules $h_{c}\left(a_{t}, \varepsilon_{t}\right)$ and $h_{a}\left(a_{t}, \varepsilon_{t}\right)$. Given $\Gamma_{0}\left(a_{0}, \varepsilon_{0}\right)$, the distribution evolves with the law of motion defined by

$$
\Gamma_{t+1}\left(a_{t+1}, \varepsilon_{t+1}\right)=\sum_{\varepsilon_{t+1} \in E} \Pi\left(\varepsilon_{t+1} \mid \varepsilon_{t}\right) \Gamma_{t}\left(h_{a}^{-1}\left(a_{t+1}, \varepsilon_{t}\right), \varepsilon_{t}\right) .
$$

The definition of competitive equilibrium under financial integration is given below.

Definition 1 (Financial integration) Initial joint distributions of individuals across both individual wealth and labor efficiency shocks in the two economies are given by $\Gamma_{0}\left(a_{0}, \varepsilon_{0}\right)$ and $\Gamma_{0}^{*}\left(a_{0}^{*}, \varepsilon_{0}^{*}\right)$. Idiosyncratic risk washes out in aggregate. Given initial distributions, net foreign asset positions, $B_{0}, B_{0}^{*}$, public debt $D_{0}, D_{0}^{*}$, capital stock $K_{0}, K_{0}^{*}$, fiscal policy instruments $\left\{G, G^{*}, \tau, \tau, \tau^{k}, \tau^{k *}\right\}$, a general equilibrium under financial integration is defined by

1. Households' policy functions $\left\{h_{c}\left(a_{t}, \varepsilon_{t}\right), h_{c}^{*}\left(a_{t}, \varepsilon_{t}\right), h_{a}\left(a_{t}, \varepsilon_{t}\right), h_{a}^{*}\left(a_{t}, \varepsilon_{t}\right)\right\}_{t=0}^{\infty}$

2. A competitively determined, deterministic path of relative prices $\left\{w_{t}, w_{t}^{*}, r_{t}^{d}, r_{t}^{d *}\right.$,

$$
\left.r_{t}^{k}, r_{t}^{k *}, r_{t}\right\}_{t=0}^{\infty}
$$

3. A deterministic path of aggregates $\left\{C_{t}, C_{t}^{*}, A_{t+1}, A_{t+1}^{*} K_{t+1}, K_{t+1}^{*}\right.$,

$$
\left.B_{t+1}, B_{t+1}^{*}, D_{t+1}, D_{t+1}^{*}\right\}_{t=0}^{\infty}
$$

4. Distributions $\left\{\Gamma_{t}\left(a_{t}, \varepsilon_{t}\right), \Gamma_{t}^{*}\left(a_{t}^{*}, \varepsilon_{t}\right)\right\}_{t=1}^{\infty}$ 
such that:

- Given the sequences of plans and policies, the plans are optimal for individuals and firms.

- The aggregates are consistent with household behavior:

$$
\begin{gathered}
\int_{(a, \varepsilon)} c_{t}\left(a_{t}, \varepsilon_{t}\right) d \Gamma_{t}=C_{t}, \int_{(a, \varepsilon)} a_{t}\left(a_{t-1}, \varepsilon_{t-1}\right) d \Gamma_{t}=A_{t}, \text { for all } t . \\
\int_{(a, \varepsilon)} c_{t}^{*}\left(a_{t}, \varepsilon_{t}\right) d \Gamma_{t}^{*}=C_{t}^{*}, \int_{(a, \varepsilon)} a_{t}^{*}\left(a_{t-1}, \varepsilon_{t-1}\right) d \Gamma_{t}^{*}=A_{t}^{*}, \text { for all } t .
\end{gathered}
$$

- Labor market clears in each country:

$$
\int_{(a, \varepsilon)} \varepsilon_{t} n d \Gamma_{t}=N \text { and } \int_{(a, \varepsilon)} \varepsilon_{t} n^{*} d \Gamma_{t}^{*}=N^{*}
$$

- Goods market clears:

$$
C_{t}+C_{t}^{*}+I_{t}+I_{t}^{*}+G+G^{*}=F\left(K_{t}, N\right)+F\left(K_{t}^{*}, N^{*}\right) \text {, for all } t .
$$

- Asset market clears:

$$
A_{t}+A_{t}^{*}=K_{t}+K_{t}^{*}+D_{t}+D_{t}^{*}, \text { for all } t .
$$

- The government budget holds in each country for all $t$.

- The sequence of distributions $\Gamma_{t}, \Gamma_{t}^{*}$ is consistent with the initial distribution, individual policies and idiosyncratic shocks for $t \geq 1$.

The resource constraint in Home can be written as (and similarly defined for Foreign)

$$
C_{t}+I_{t}+G+B_{t+1}-B_{t}=Y_{t}+r_{t} B_{t}
$$

where $I_{t} \equiv K_{t+1}-(1-\delta) K_{t}$ is net domestic, private investment and $B_{t} \equiv A_{t}-K_{t}-D_{t}$ is the date- $t$ net foreign asset position for Home, $B_{0}, K_{0}$ and $D_{0}$ given. Then it is possible to define Home current account, $C A_{t} \equiv B_{t+1}-B_{t}$, net exports, $N X_{t} \equiv B_{t+1}-B_{t}\left(1+r_{t}\right)$ and net factor payments, $N F P_{t} \equiv r_{t} B_{t}$ which can be defined similarly for Foreign. 


\subsection{Characterizing the equilibrium}

The first order conditions from the optimization problems above are given below.

1. Firm optimization implies

$$
\begin{aligned}
& r_{t}^{k}=F_{K}\left(K_{t}, N\right) . \\
& w_{t}=F_{N}\left(K_{t}, N\right) .
\end{aligned}
$$

The conditions for Foreign can be defined similarly. Hence factor prices in a given country depend on the aggregate capital and labor in that country.

2. Household optimization yields

$$
\left[c\left(s_{t}\right)\right]^{-1}=\beta E_{\varepsilon_{t+1} \mid \varepsilon_{t}}\left(1+r_{t+1}\right)\left(\left[c\left(s_{t+1}\right)\right]^{-1}+\tilde{\lambda}\left(s_{t+1}\right)\right),
$$

where and $\tilde{\lambda}$ is the Lagrange multiplier associated with the borrowing constraint. Again, similar conditions can be expressed for Foreign.

\section{Qualitative effects of a capital income tax cut}

The tax reform occurs at $t=0$, when the world economy is in the steady state. The Home government introduces a permanent, unanticipated capital income tax cut, and adjusts the progressive tax parameter, $\tau_{n}$ and the sequence of public debt $\left\{D_{t+1}\right\}_{t=0}^{\infty}$, in order to compensate for the lost revenue. The impact of the Home reform is then transmitted to the budget of the government in Foreign, through changes in domestic and international prices and allocations, requiring a once-and-for all change in $\tau_{n}^{*}$ to maintain fiscal solvency. Hence, Foreign introduces a tax reform at $t=0$ as well.

In this section, following Aiyagari (1995), I provide some intuition on how tax reforms affect the steady-state allocations and how these results compare to those of a closed economy. I start with explaining how the international interest rate is determined in the steady state. Assume that the production function is defined as Cobb-Douglas, $K^{\alpha} N^{1-\alpha}$ where $\alpha$ is the share of capital in production and also assume a general case in which labor supply is elastic.

Optimal portfolio choice in addition to firm's optimization implies that Home after-tax net return to capital is equal to the interest rate: 


$$
\left(r^{k}-\delta\right)\left(1-\tau_{k}\right)=\left(\alpha K^{\alpha-1} N^{1-\alpha}-\delta\right)\left(1-\tau_{k}\right)=r
$$

and similarly in Foreign:

$$
\left(r^{k *}-\delta\right)\left(1-\tau_{k}^{*}\right)=\left(\alpha K^{* \alpha-1} N^{* 1-\alpha}-\delta\right)\left(1-\tau_{k}^{*}\right)=r
$$

In an equilibrium with financial integration, these two conditions must yield:

$$
r=\left(\alpha K^{\alpha-1} N^{1-\alpha}-\delta\right)\left(1-\tau_{k}\right)=\left(\alpha K^{* \alpha-1} N^{* 1-\alpha}-\delta\right)\left(1-\tau_{k}^{*}\right)
$$

Therefore, after-tax net returns to physical capital are equalized across countries under financial integration. If an equilibrium with $\tau_{k} \neq \tau_{k}^{*}$ exists, this implies cross-country differences in aggregate equity and employment. In particular, if $\tau_{k}<\tau_{k}^{*}$, aggregate capital-aggregate labor ratio in Home is greater than Foreign, i.e. $K / N>K^{*} / N^{*}$. Notice that if physical capital were traded internationally and households paid taxes according to the residence principle then optimality would require that cross-country capital income tax rates be equalized, $\tau_{k}=\tau_{k}^{*}{ }^{7}$

Moreover, government's steady-state budget constraint can be expressed as follows:

$$
K+D=\frac{K}{1-\tau_{k}}+\frac{T R-G}{r}
$$

and

$$
K^{*}+D^{*}=\frac{K^{*}}{1-\tau_{k}^{*}}+\frac{T R^{*}-G^{*}}{r} .
$$

For a given set of taxes and government expenditures, the $K+D$ curve is decreasing in $r$ for both countries. This is because as $r$ rises, $r^{k}$ rises and $w$ falls. This implies lower $K / N$ and lower $N$. Hence, $K$ is also lower. As $r \rightarrow \infty, K, N$ and $w \rightarrow 0$. On the other hand, if $r \rightarrow 0$, then $K, N$ and $w \rightarrow \infty$. The supply of assets are determined by the

\footnotetext{
${ }^{7}$ The residence principle requires that Home households are imposed with the same tax rate for their domestic and foreign capital holdings. If equity were traded internationally and under the resident principle, the optimal portfolio allocation for Home residents would imply $r=\left(\alpha K^{\alpha-1} N^{1-\alpha}-\delta\right)\left(1-\tau_{k}\right)=$ $\left(\alpha K^{* \alpha-1} N^{* 1-\alpha}-\delta\right)\left(1-\tau_{k}\right)$ where $K=K_{1}+K_{2}$ is the total domestic equity, $K_{1}$ is the (aggregate) domestic equity holding of Home residents and $K_{2}$ is the (aggregate) domestic equity holding of Foreign residents. A similar condition for Foreign residents can be stated as $r=\left(\alpha K^{\alpha-1} N^{1-\alpha}-\delta\right)\left(1-\tau_{k}^{*}\right)=$ $\left(\alpha K^{* \alpha-1} N^{* 1-\alpha}-\delta\right)\left(1-\tau_{k}^{*}\right)$ where total foreign equity can be defined similarly, $K^{*}=K_{1}^{*}+K_{2}^{*}$. In this case, cross-country capital tax rates would be equalized. Note also that even if countries differed in terms of total factor productivity parameters this result would not change.
} 
household's problem and as defined above, aggregate household savings in each country are given by $\int_{s} a d \Gamma=A$ and $\int_{s} a^{*} d \Gamma^{*}=A^{*}$. As shown by Aiyagari (1994a,b; 1995), $A$ is an increasing function of $r$ (which follows from the fact that household policy functions are increasing in $r$ for each country. The equations (20)-(22) along with households' aggregate savings determine the equilibrium in the world asset market. Furthermore, under market incompleteness, aggregate asset holdings tend to infinity as $r$ approaches the rate of time preference, $1 / \beta-1$ from below. As discussed by Aiyagari (1994a,b; 1995), a household wants to maintain a smooth marginal utility of consumption when $r=1 / \beta-1$. If households face uninsurable labor income risk, however, the possibility of having bad income shocks in the future requires households to accumulate infinite amount of assets in order to maintain a smooth marginal utility of consumption profile.

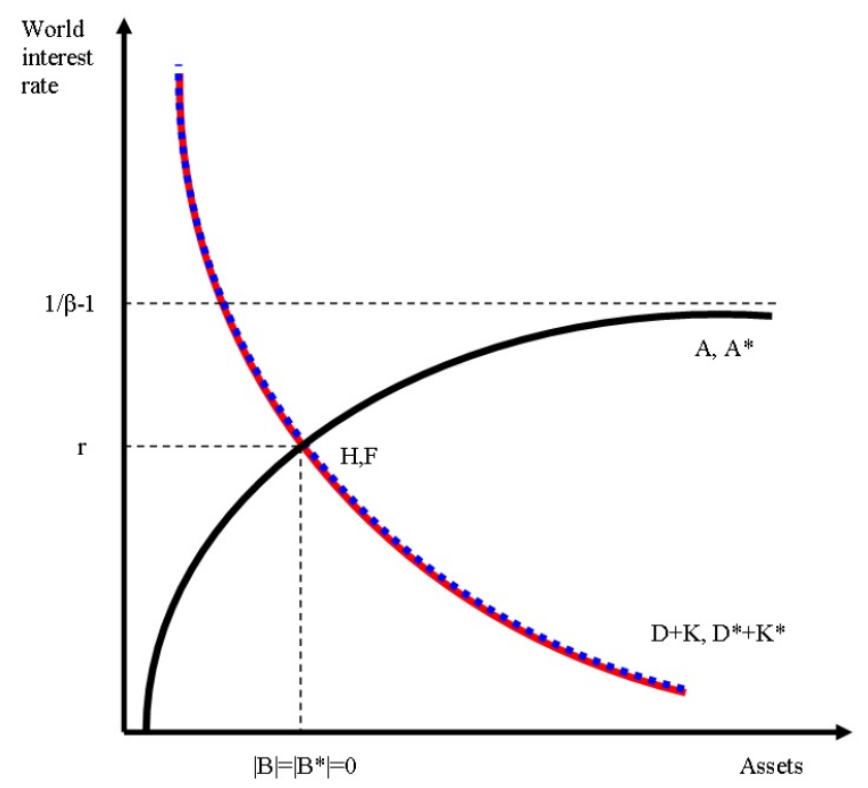

Figure 1: Steady-state equilibrium under financial integration where countries have identical fiscal policy parameters and balanced trade

An equilibrium with financial integration exists if there exists a steady-state interest rate $r$ that clears the market, i.e.

$$
B(r)+B^{*}(r)=A(r)-K-D+A^{*}(r)-K^{*}-D^{*}=0,
$$


If countries are symmetric, i.e. if they have identical technologies, populations and/or government policies, there exists an equilibrium with balanced trade (or zero net foreign asset position), i.e.

$$
B(r)=0 \text { and } B^{*}(r)=0,
$$

and the equilibrium allocations would be identical to those under financial autarky.

While the world is in equilibrium, assume that the capital income tax in Home, $\tau_{k}$ is lower. This implies the asset demand curve for Home, $K+D$ will shift to the right of the asset demand curve for Foreign (See Figure 2).

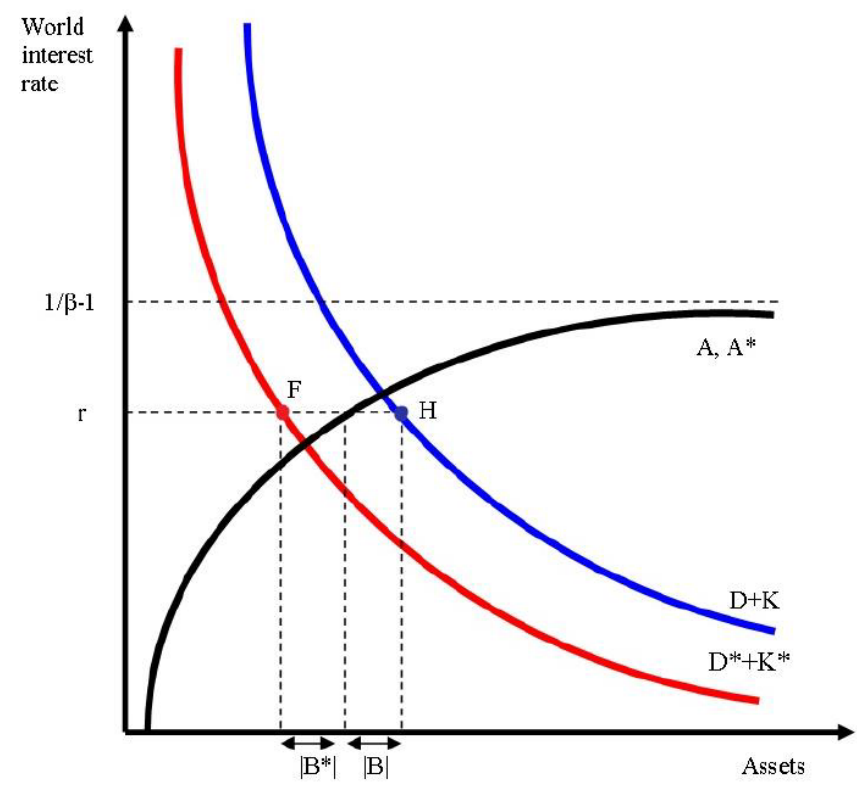

Figure 2: Pre-reform steady-state equilibrium where Home imposes a lower capital income tax than Foreign

The logic is as follows. For a given world interest rate $r$, if $\tau_{k}$ is lower $r_{k}$ is lower and $K / N$ ratio and $K$ is higher (See equation (21); similar logic applies to Foreign by equation (22); which implies $w$ is higher and $K$ is higher.

As a result, there is excess supply of capital in Home and excess demand for capital in Foreign yielding a lower (negative) foreign asset position for Home and a higher (positive) foreign asset position for Foreign at the equilibrium interest rate, i.e. for a given world 
interest rate $r$,

$$
B(r)=A(r)-K-D<0
$$

and

$$
B^{*}(r)=A^{*}(r)-K^{*}-D^{*}>0 .
$$

A more realistic scenario however, is when countries are allowed to be asymmetric due to differences in their policy and/or technology parameters, which is also the scenario adopted throughout the quantitative analyses of this paper. Under the asymmetric case, the initial asset supply and demand curves will lie in different positions than depicted in Figure 1. However, the effect of a unilateral capital income tax cut in Home will be qualitatively similar: it will shift the demand curve to the right. Cross-country differences in labor income taxes, government expenditures, or public debt stock further contribute to shifts in these curves. Also, the asset supply curves do not necessarily overlap.

The dynamics of the reform is complicated and a quantitative experiment is required to see how the government debt stock evolves and the new labor income tax is determined in response to a capital tax cut. In this framework, the post-reform steady state equilibrium allocations are solved simultaneously with the transition path. The next section explains these dynamics in greater detail.

\subsection{Numerical solution and calibration}

The solution of the problem involves two steps (i) an algorithm that solves for the equilibrium path for prices and aggregate variables and (ii) the solution for households' decision rules.

The first step starts with assuming the post-tax steady state is converged at time $T$. The post-reform steady state can be computed once the levels of public debt, $D_{T}$ and $D_{T}^{*}$ are known. These however, depend on their values in the transition path, and therefore the final steady state and the transition path must be computed simultaneously. After computing the pre-reform steady state, the post-reform steady state and the transition path are computed. Once a guess for the transition path of capital and prices has been made, it is possible to determine a unique value for the post-reform labor income tax parameter $\tau_{n}$ and $\tau_{n}^{*}$, that satisfies the present value of the government's budget in each country.

The second step is, to compute households' decision rules given prices and government policy parameters. In order to solve for the decision rules of households, I implement an 
Euler equation-based method that blends the time-iteration method by Coleman (1990) with the endogenous grid point method (EGM) by Carroll (2006). ${ }^{8}$

Following the country selection of Chen, İmrohoroğlu, and İmrohoroğlu (2009) who study the US current account deficit in a two country growth model, I calibrate the model to match the US and rest of the world (ROW) macroeconomic aggregates where the ROW consists of OECD countries except for the US. This calibration also yields a realistic wealth distribution for the US. For the ROW the resulting distributions are comparable with the remaining OECD countries. The model period is one year and the calibration of the model targets are based on annual data.

Preferences and Technology: Benchmark model parameterization is summarized in Table 1. Accordingly, the production function is Cobb-Douglas, given by $Z K^{\alpha} N^{1-\alpha}$ with a capital's share in output, $\alpha$ is 0.36 , and the depreciation rate, $\delta$ is 0.06 for both countries. The discount rate $\beta$ is set at 0.971 and the resulting steady state capital-output ratio is 3.53 for the US and 3.45 for the ROW. As Mendoza, Quadrini, and Rios-Rull (2007) also argue, any combination of productivity and population parameters that to match the GDP ratios would generate a realistic path for international capital flows. I allow each country to have a unit mass of population. By normalizing the ROW parameter $Z^{*}=1$ and setting $Z=0.6$ for the US, the model is able to capture a realistic GDP share for the US in the world given by $31.3 \%$. This is close to the 2000-2015 average in the data (World Development Indicators, GDP in constant 2010 dollars) which was $33 \%$.

Borrowing limits: In the benchmark calibration, there is no borrowing and $\underline{a}=0$. This assumption will be relaxed in Section 4.3.3 to study the implications of a negative borrowing limit.

Labor earnings process: These are taken from Domeij and Heathcote (2004) where it is assumed that there are three productivity shock levels, $E=\left\{\varepsilon^{h}, \varepsilon^{m}, \varepsilon^{l}\right\}$ with $\varepsilon^{h}=4.74$, $\varepsilon^{m}=0.847$ and $\varepsilon^{l}=0.170$, and these are identical in both countries. The transition

\footnotetext{
${ }^{8}$ Carroll (2006) applies this technique on the consumption problem using an otherwise standard value function iteration. In particular, EGM involves changing the time convention of asset grid points so that the grid points are defined over next period's assets instead of the current period, which helps improve speed. This method has been tried in a Bewley-style envrionment by Guerrieri and Lorenzoni (2011) and in a standard Aiyagari model by Rendahl (2015). Kabukçuoğlu and Martinez-Garcia (2016) extend this method to solve problems with multiple choice variables and show that it can provide speed gains compared to Howard's policy improvement algorithm.
} 
probabilities are given by

$$
\Pi=\left[\begin{array}{ccc}
\Pi_{11} & 1-\Pi_{11} & 0 \\
\frac{1-\Pi_{22}}{2} & \Pi_{22} & \frac{1-\Pi_{22}}{2} \\
0 & \Pi_{11} & 1-\Pi_{11}
\end{array}\right]=\left[\begin{array}{ccc}
0.90 & 0.10 & 0 \\
0.005 & 0.99 & 0.005 \\
0 & 0.10 & 0.90
\end{array}\right]
$$

The implies steady-state probability distribution is given by $p^{*}=\left[\begin{array}{ll}0.0455 & 0.9091\end{array}\right.$ $0.0455]$.

Government policy: I set the progressivity parameters $\psi=0.849$ and $\psi^{*}=0.849$ for both countries following Heathcote, Storesletten, and Violante (2014) who provide an estimate for the US focusing only on labor income. This estimate is based on the Panel Study of Income Dynamics (PSID) survey data for 2000, 2002, 2004 and 2006 and for households aged 25-60 (and hence working population). In the calibration of the other tax parameters, I target Canada which stands as the median country in the average effective labor and capital income taxes among G7 countries for which these estimates are available. In particular, I set $\tau^{n}=0.73$ and $\tau^{n *}=0.67$ which generate income tax revenues-to-GDP ratios, $20.6 \%$ for the US and $30.3 \%$ for the ROW in the model. This is close to the ratios in the data in 2010, according to Chang, Chang, and Kim (2016), reporting values of $23.8 \%$ for the US and $30.6 \%$ for Canada. For other OECD countries, these values range between $19.5 \%$ (Chile) and $47.4 \%$ (Denmark). The US capital income tax, $\tau^{k}$ is set at 0.397 , which is the 2009 estimate by Landry (2011), using the methodology of Mendoza, Razin and Tesar (1998). For the ROW, the estimate for Canada, 0.425 is used. Finally, I set the initial public debt-to-GDP ratios $D_{0} / Y_{0}$ and $D_{0}^{*} / Y_{0}^{*}$ at 0.70 and 0.94 , respectively to match the US and ROW public debt-to-GDP ratios. For the US, in the 2000-2015 period, this average for this ratio was 70\% (Central Government Debt from World Development Indicators), which is the same in the model. For rest of the OECD countries where these series are available only for the $2010-2013$ period, the average of the ratio is $93.7 \%$. The level of government spending is not a free parameter in the model, and is determined by the calibration of the level of public debt. Hence, there are relatively large discrepancies in the value of government spending-to-GDP ratios between the model and the data. The respective government spending-to-GDP ratios for the two countries in the model are $18.8 \%$ and $27.9 \%$. On the other hand, according to data in the 2000-2015 period (Central Government Final Consumption Expenditure from World Development Indicators), the averages for these ratios were $16.5 \%$ and $19.4 \%$, respectively. 
Table 1: Parameterization in the pre-reform steady state

\begin{tabular}{lccccccccc}
\hline \hline Technology, preferences & $Z$ & $Z^{*}$ & $\alpha$ & $\beta$ & $\delta$ & $\underline{\mathrm{a}}$ & & \\
\& borrowing limit & 0.6 & 1 & 0.36 & 0.971 & 0.06 & 0 & & \\
\cline { 1 - 6 } Government policy & $D_{0} / Y_{0}$ & $D_{0}^{*} / Y_{0}^{*}$ & $\psi$ & $\psi^{*}$ & $\tau^{n}$ & $\tau^{n *}$ & $\tau^{k}$ & $\tau^{k *}$ \\
& 0.70 & 0.94 & 0.849 & 0.849 & 0.73 & 0.67 & 0.397 & 0.425 \\
\hline
\end{tabular}

This parameterization results in the following allocations for the two countries relative to GDP. Overall, the model does fairly well in matching the investment and the trade balances of the two countries in the data that come from World Development Indicators, 2000-2015 averages for the US and rest of OECD. ${ }^{9}$

Table 2: Macroeconomic aggregates in the pre-reform steady state (\%)

\begin{tabular}{lllll}
\hline \hline & US & \multicolumn{3}{l}{ ROW } \\
& Model & Data & Model & Data \\
Investment/GDP & 21.2 & 20.4 & 20.7 & 21.8 \\
Government spending/GDP & 18.8 & 16.0 & 27.9 & 19.4 \\
Trade balance/GDP & -2.2 & -4.2 & 0.8 & 1.3 \\
Public debt/GDP & 70 & 70 & 93.7 & 93.7 \\
Tax revenues/GDP & 20.6 & 23.8 & 30.3 & 30.6 \\
\hline
\end{tabular}

The second part of the calibration strategy targets the wealth distributions. Since the parameterization of the earnings shock process used for both countries are identical, the wealth distributions exhibit slight differences only due to the differences between government and technology parameters. Table 3 reports the asset holding distributions of households across different quintiles in the US and ROW under financial integration. Accordingly, the distributions implied by the model are comparable to those from the data for the US based on the 2007 Survey for Consumer Finances (SCF) statistics reported by

\footnotetext{
${ }^{9}$ Investment: Gross fixed capital formation, 2010 US dollars. Trade balance: Exports of goods of services net of imports of goods and services, 2010 US dollars.
} 
Diaz-Gimenez, Glover, and Rios-Rull (2011).

Table 3: Distributional properties of the pre-reform steady-state in the US

\begin{tabular}{cccc}
\hline \hline & \multicolumn{3}{c}{ Wealth distribution } \\
Quintiles & Model (US) & Model (ROW) & US Data (SCF) \\
Q1 & $0.9 \%$ & $1 \%$ & $-0.2 \%$ \\
Q2 & $1.4 \%$ & $1.2 \%$ & $1.1 \%$ \\
Q3 & $3.6 \%$ & $3.5 \%$ & $4.5 \%$ \\
Q4 & $19.0 \%$ & $18.9 \%$ & $11.2 \%$ \\
Q5 & $75.2 \%$ & $75.4 \%$ & $83.4 \%$ \\
\hline
\end{tabular}

In the model, the poorest $20 \%$ of the population (the first quintile) hold only $0.9 \%$ of the total wealth in the US economy, whereas the richest $20 \%$ (the fifth quintile) hold $75.2 \%$, mimicking the high wealth inequality in the US especially by matching the bottom tail of the wealth distribution. The data however, exhibit greater inequality, where the bottom quintile of the distribution holds $-0.2 \%$ of the total wealth and the top quintile of the distribution has $83.4 \%$. The model-implied wealth Gini $(0.71)$ is also close to the data $(0.85) \cdot{ }^{10}$

For the rest of the OECD countries, wealth distribution data are limited and also not very standardized across countries (See Chang, Chang, and Kim (2016) for a discussion.) I use the Credit Suisse report on OECD by Davies, Lluberas, and Shorrocks (2012) as a reference. The model generates a wealth Gini of 0.72 for Foreign that matches the 2012 average for these countries in the data. Accordingly, the most even wealth distribution is in Japan (0.596) while the most uneven wealth distribution is in Turkey (0.842). Given this range, the model's fit for overall wealth distribution for the rest of the world can be considered realistic.

It is not possible to generate exactly the same allocations, prices or wealth distributions under the closed and open-economy models since under a realistic calibration the trade balances will be non-zero in the open-economy framework. The differences, however, are not large. Also, it should be noted that the current paper focuses on the open-economy model as the more realistic scenario and uses the closed economy framework only to facilitate a comparison with the earlier studies.

\footnotetext{
${ }^{10}$ It is harder to match the top tail of the wealth distribution in standard Aiyagari-style models. In the current model, the richest $1 \%$ and $5 \%$ own $22 \%$ and $40.9 \%$ of the total wealth, respectively.
} 


\section{Results}

\subsection{Macroeconomic consequences of tax reform}

First, I present the impact of the tax reform on macroeconomic aggregates. While the world economy is at the steady-state, the Home capital income tax is replaced by higher labor income taxes that differ across households labor earnings. The reform is permanent and unanticipated. The Home tax reform affects world prices and induces a change in the capital stock and the ability to raise income tax revenues in Foreign. In turn, this induces Foreign government to make adjustments in the budget constraint by altering the average labor income taxation, captured by $\tau^{n *}$. The values of tax parameters in the benchmark experiment as well as the initial and final allocations and interest rates are summarized in Table 4.

Table 4: Pre- and post-reform taxes, steady-state allocations, and prices

\begin{tabular}{lllllll}
\hline \multicolumn{9}{c}{ Financial integration } & \multicolumn{3}{c}{ Autarky } \\
& \multicolumn{2}{c}{ Home } & \multicolumn{2}{c}{ Foreign } & & Home \\
& Initial & Final & Initial & Final & Initial & Final \\
$\tau^{k}$ & 0.397 & 0.000 & 0.425 & 0.425 & 0.397 & 0.000 \\
$\tau^{n}$ & 0.730 & 0.627 & 0.670 & 1.016 & 0.730 & 0.616 \\
$K / Y$ & 3.53 & 4.25 & 3.46 & 3.49 & 3.56 & 4.18 \\
$D / Y$ & 0.70 & 0.83 & 0.94 & 1.07 & 0.70 & 1.02 \\
$G / Y$ & 0.19 & 0.17 & 0.28 & 0.28 & 0.19 & 0.20 \\
$T B / Y$ & -0.02 & 0.03 & 0.01 & -0.02 & 0 & 0 \\
$Y$ & 0.92 & 1.02 & 2.01 & 2.02 & 0.92 & 1.01 \\
$r(\%)$ & 2.54 & 2.48 & & & 2.48 & 2.62 \\
\hline
\end{tabular}

Figure 3 shows the dynamics of economy-wide variables. ${ }^{11}$ The key macroeconomic changes in response to the reform for Home and Foreign, as well as Home under financial autarky can be discussed in three dimensions : i) long run gains vs. short run costs, ii) adjustment in prices and iii) adjustment in labor income taxes.

\footnotetext{
${ }^{11}$ While the transition path to the new steady state in the benchmark model is 300 years long, the length of the transition path varies across experiments throughout the paper.
} 

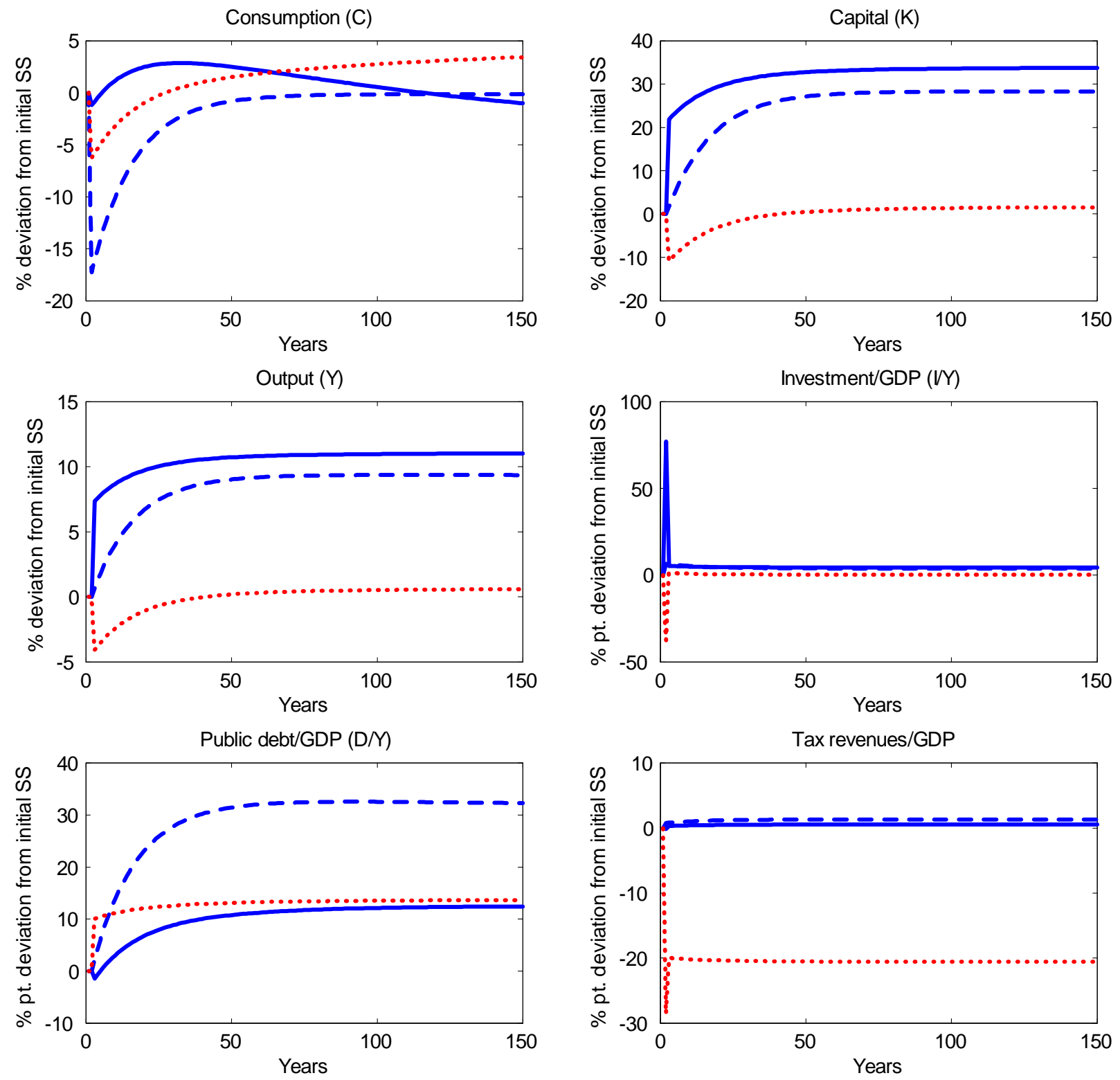

- - Home $(\mathrm{FA}) \longrightarrow$ Home $(\mathrm{FI}) \cdots$ Foreign

Figure 3: Post-reform transition dynamics

i) Long run vs. short run: The reform stimulates investment and output in the long 
run in Home, and international borrowing enables the rise in these two variables to be greater relative to autarky. As more resources are allocated towards investment, the reform requires that Home residents need to sacrifice some of their consumption in the short run. This fall in consumption is more drastic under financial autarky than financial integration.

With access to international financial markets, rising investment in Home can be financed via Foreign resources, in addition to domestic resources and therefore the transition cost becomes less severe. This helps Home consumption path to recover fast and go above its pre-reform level in the medium run. This pattern is reversed and aggregate consumption starts to fall as the country starts paying interest income to Foreign. Indeed, Foreign suffers an initial loss in consumption, capital, and output which exhibit a gradual increase in subsequent periods.

The changes in aggregate consumption between the two steady states are $-2.8 \%, 4.1 \%$ for Home and Foreign under financial integration, respectively, and $-0.1 \%$ for Home under financial autarky.

Figure 4 shows the response of the wealth and external accounts after the reform. A dramatic change in capital income tax in Home results in a drastic deterioration (improvement) of Home (Foreign) current account, net foreign assets, trade balance and factor payments. On impact, Home current account-to-GDP ratio deteriorates by about 75 percentage points relative to the initial steady state, whereas the trade balance-to-GDP ratio falls by about 73 percentage points. The reform also prompts a large wealth accumulation in Foreign, by about 30\% increase between the steady states, whereas Home accumulates wealth on impact and then starts reducing it which occurs primarily due to its wealth transfer to Foreign.

The changes in a country's wealth have important implications on welfare as it affects households' ability to buffer against idiosyncratic labor income risk and smooth their consumption in the presence of borrowing constraints. 

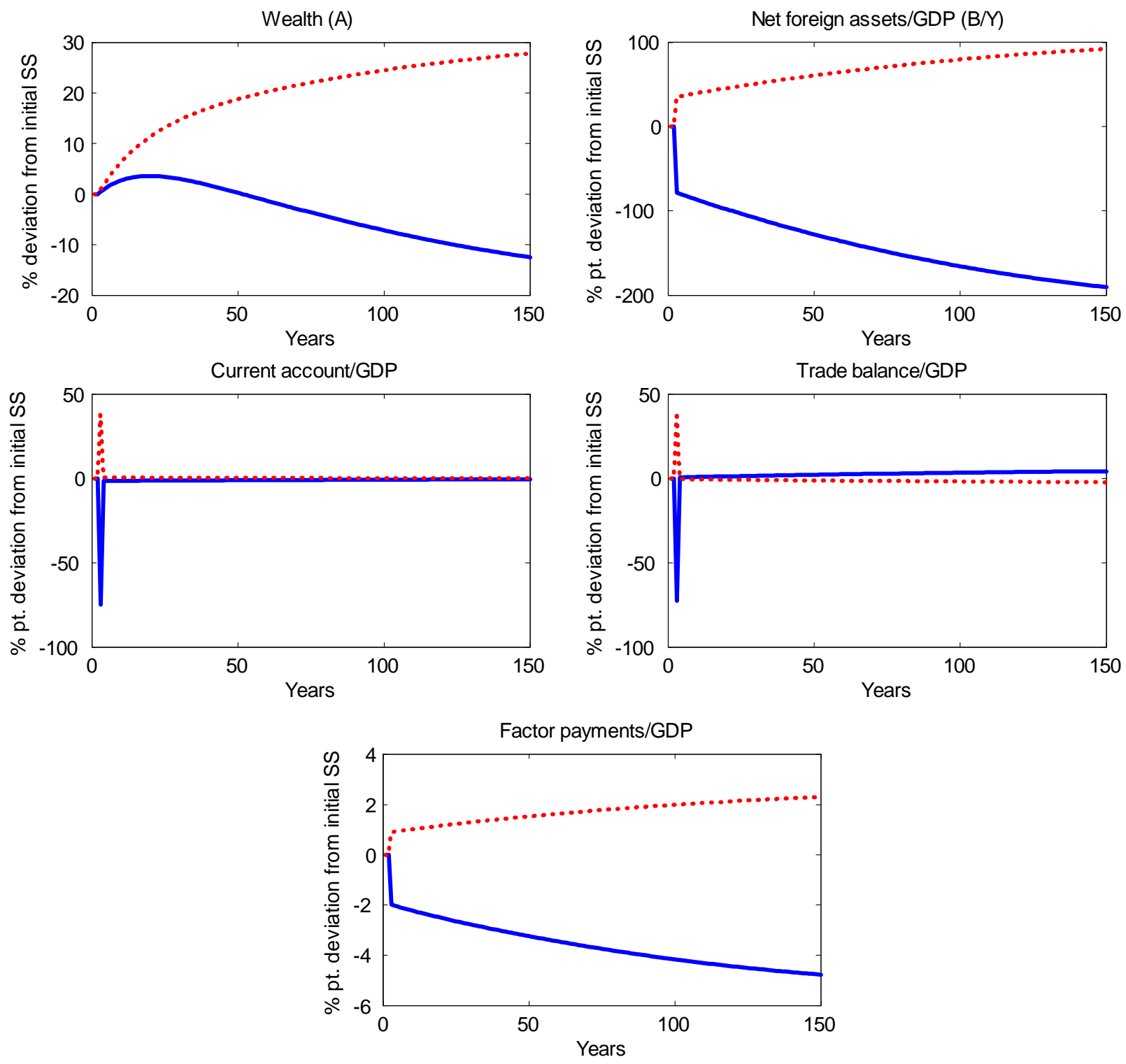

Home ....... Foreign

Figure 4: Post-reform transition dynamics 

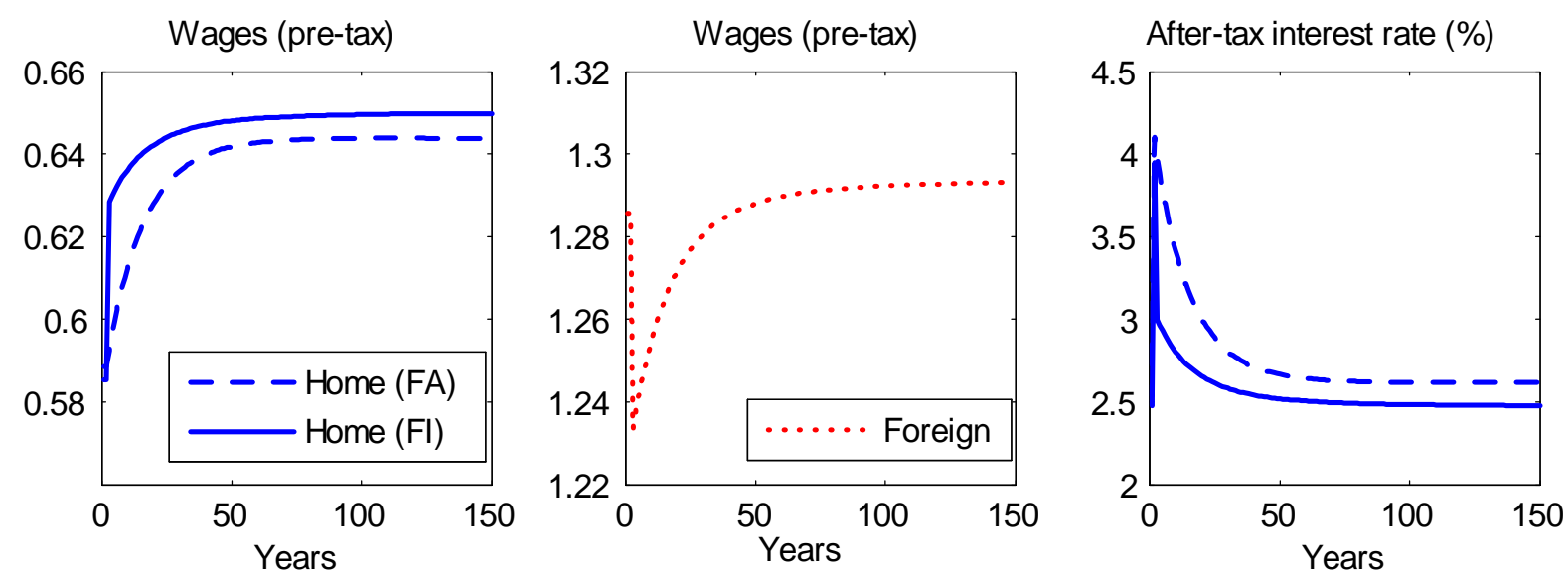

Figure 5: Post-reform price dynamics

ii) Adjustment in prices: Figure 5 depicts the transition path for the after-tax (world) interest rate and pre-tax wages. The impact effect of a capital income tax cut is a rise in the world interest rate. As the Home and Foreign physical capital stock adjusts, the world interest rate starts to decline falling from $2.54 \%$ in the initial steady state to $2.48 \%$ in the final steady state. During the transition, the open economy is able to generate greater capital accumulation than the autarkic economy, which leads to a relatively modest change in the after-tax interest rate. An increase in the interest rate enables a better ability to do consumption smoothing as it implies higher asset returns and the borrowing limit is zero. In turn, the opposite of this effect can be pronounced for (pre-tax) wages: Home wages under financial integration go up by more than those under financial autarky. Foreign wages decline first, and then rebound as the country accumulates more capital.

iii) Labor income tax adjustment: After the elimination of the Home capital income tax, the only source of tax revenues to the government is due to labor income. Greater capital accumulation has a positive impact on (pre-tax) labor earnings under financial integration, which relaxes the government's need to raise labor income taxes to finance a given amount of government spending.

An increase in the world interest rate affects the other interest rates in the economy through the no-arbitrage condition and imposes a greater cost on financing the public debt. But as an open economy, the cost to Home through this channel rises by less since the interest rate also rises by less and eventually falls below its initial steady state value. 
Despite this fact, the closed economy accumulates greater public debt as it has a greater need to compensate the loss in capital income tax revenues.

Movements in pre-tax wages and governments' need to change average labor income taxation jointly determine the movements in after-tax labor income of households across different productivity levels. Even though Home after-tax labor income fall after the reform, they start recovering as more capital is accumulated. Whether they go above their pre-reform steady state levels or not is determined by the size of capital accumulation. The quantitative exercise shows that under financial integration, after-tax labor income rises above the pre-reform levels, whereas in the autarkic economy they remain below.

In all the model economies for Home, households pay labor income taxes as a function of their earnings level. Foreign households are also subject to progressive labor income taxes, but the solution path suggests that Foreign households that are at the medium and low productivity levels receive subsidies, rather than pay taxes, as presented in terms of negative values of labor income taxes. In fact, 95.5\% of Foreign residents benefit from government transfers. This massive provision of subsidies becomes feasible as Foreign still has an alternative source of tax revenues, i.e. capital, and enjoys a wealth expansion along the transition path.

Accordingly, the percentage change in after-tax labor income between the two steady states is $0.8 \%$ in Home (financial integration), $52 \%$ in Foreign and $-2.1 \%$ in Home (financial autarky). The relatively modest increase in after-tax wages in Home under financial integration helps the poor. The opposite holds true under financial autarky. For Foreign these dramatic increases in the labor income bring very large gains to the economy, which are reported in the next section.

The model produces rich macroeconomic dynamics that nevertheless gives us only a partial idea about the welfare consequences of the reform. Taking into a realistic wealth distribution for the US and the rest of the OECD, the next section discusses how the potential gains and losses of the reform may be distributed across households from various wealth and productivity levels. 

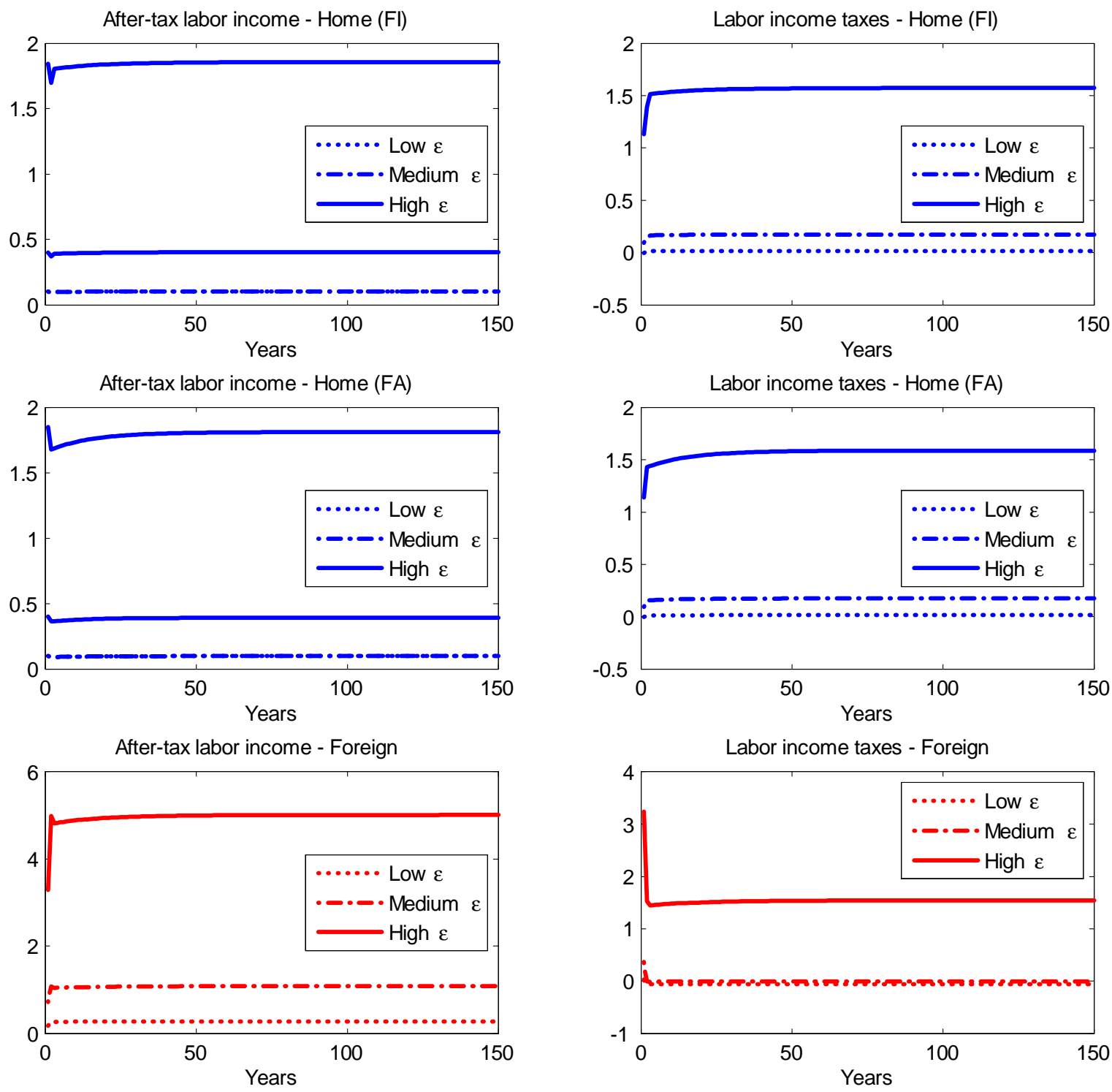

Figure 6: Post-reform transition dynamics of after-tax labor income and progressive taxes 


\subsection{Welfare consequences of tax reform}

Now I look more closely at households and welfare implications on them. More specifically, I calculate the fractions of population in favor of the tax reform under financial integration and autarky, using the initial distributions of households before the reform experiment which matches certain characteristics of the wealth distribution observed in the US and OECD data. I then compute the consumption equivalent welfare gain for a household with a given state pair $\left(a_{0}, \varepsilon_{0}\right)$ where the welfare gain for a household is defined as $g\left(a_{0}, \varepsilon_{0}\right)$ that solves

$$
E_{0} \sum_{t=0}^{\infty} \beta^{t} U\left(c_{t}^{N R}\left(1+g\left(a_{0}, \varepsilon_{0}\right)\right)\right)=E_{0} \sum_{t=0}^{\infty} \beta^{t} U\left(c_{t}^{R}\right)
$$

where $c_{t}^{N R}$ is the consumption if no reform occurs, and $c_{t}^{R}$ is the consumption under the tax reform. Therefore, $g\left(a_{0}, \varepsilon_{0}\right)$ is the proportional increase in the consumption of a household under status quo that would make that household indifferent between going through the reform and remaining in status quo. Figure 7 shows the welfare consequences for the households in three model economies across different wealth levels, pooling the households with different productivity levels. As can be seen from the figure, the initial wealth distribution is highly concentrated at low wealth levels.

A few conclusions emerge from Figure 7. First, households that start off as wealthpoor in Home suffer the most, with permanent welfare losses of around $10 \%$ of their consumption. However, these losses are mitigated under financial integration due to greater capital accumulation, which results in favorable movements in after-tax labor income. The opposite effect is observed under financial autarky where adverse movements in after-tax labor income exacerbate the losses to the poor. On the other hand, the decline in interest rates might play a negative role in welfare for households of all wealth levels, but this impact is less pronounced for wealth-poor households that predominantly rely on labor income and affects particularly the wealth-rich.

Lower interest rates over time cause a decline in the wealth of Home under financial integration, some of which is transferred to Foreign. For Foreign a different pattern arises. The households that are closest to the borrowing limit benefit the most. This large welfare gains for the poor in Foreign can be explained by sharp increases in government labor income subsidies after the tax reform. The interest rate patterns have similar welfare effects for Foreign residents as well, but changes in after-tax labor income appear to dwarf any welfare effect due to interest rates. In turn, an increase in the country's wealth 
along the transition path implies an increase in wealth at the household level, which provides households a greater room for consumption smoothing.

In the first row of Table 5, panel (a), the fraction of population that has a positive or zero gain from the tax reform in each economy is given. Accordingly the shares of population that are in favor of the reform (due to positive or zero expected gains) in Home are $13.3 \%$ (financial autarky) and $4.3 \%$ (financial integration). This implies that even though the gains and losses are mitigated under financial integration, with a larger effect on the gains, resulting in a much lower share of households that potentially benefit from the elimination of capital income taxes. The reform benefits all households in Foreign.

Next, I decompose households according to their initial productivity levels (See Figure 8). A household with a high productivity level before the tax reform is also more likely to accumulate a high level of assets than a household with a low productivity level given that they are equally wealthy initially - productivity shocks are positively correlated with wealth. Consequently, a household with a high productivity level is more likely to benefit from a capital income tax cut than a household with a lower productivity level. The percentage change in after-tax labor income is the same across all productivity levels, due to progressivity of taxes. This channel provides a relatively bigger gain for low productivity households particularly since they rely more on labor income. The quantitative experiment shows that the high productivity group supports the reform more, with $17.4 \%$ of the group's population. These values are $3.7 \%$ for the medium-productivity and $2.7 \%$ for the low-productivity group, respectively. (See Table 5, panel a.) Notice that the high and low productivity groups each make up only about $4.5 \%$ of the country's population, whereas the medium-productivity group constitutes the majority with $91 \%$. 

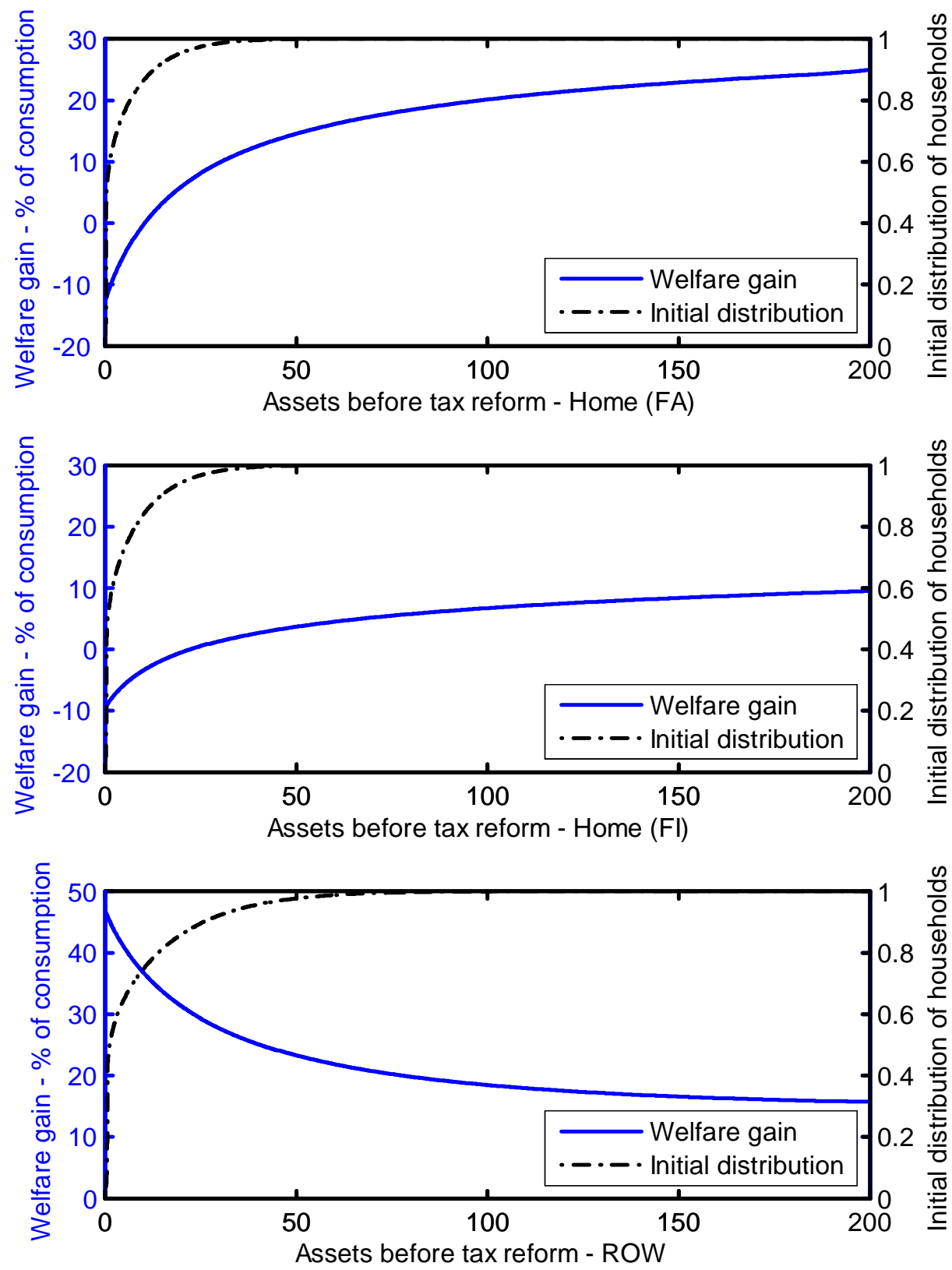

Figure 7: Welfare gains and initial distributions of households in Home (FA), Home (FI), and Foreign 

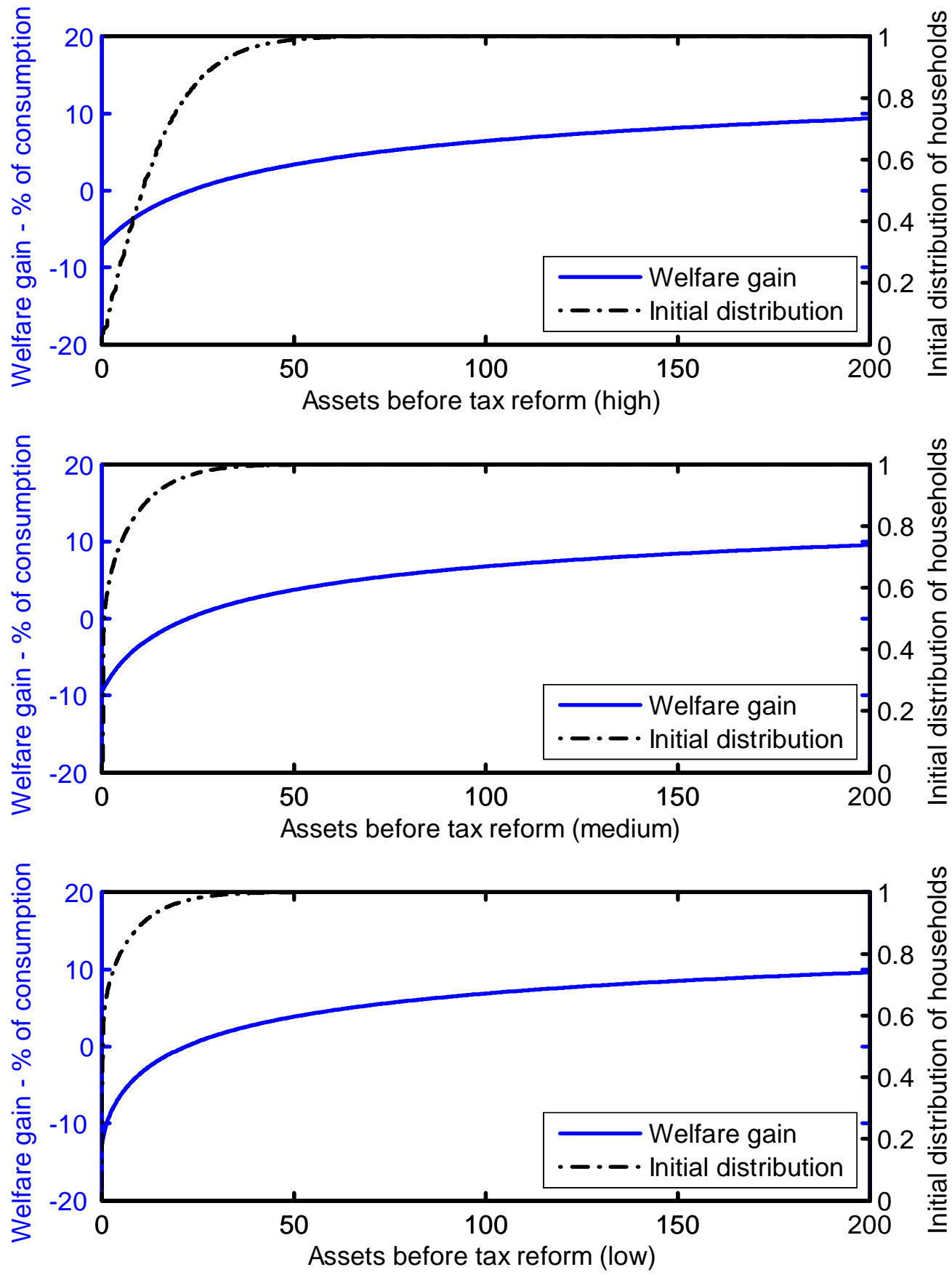

Figure 8: Welfare gains and initial distributions of households across different productivity leags in Home (FI) 
For the rest of the model economies, the fraction in favor the reform is summarized in the second and third columns of Table 5,.panel (a). For each group, the fraction that potentially benefits from the reform is larger under financial autarky. Nevertheless, none of these groups have the majority support. In Foreign, all groups gain and support the reform unanimously.

Table 5: Welfare implications of tax reform (benchmark scenario)

\begin{tabular}{lccc}
\hline \hline (a) & Home (FA) & Home (FI) & Foreign \\
Fraction in favor (100\%) & $13.3 \%$ & $4.3 \%$ & $100 \%$ \\
High (4.5\%) & $51.4 \%$ & $17.4 \%$ & $100 \%$ \\
Medium (91\%) & $11.6 \%$ & $3.7 \%$ & $100 \%$ \\
Low (4.5\%) & $8.4 \%$ & $2.7 \%$ & $100 \%$ \\
(b) & & & \\
Aggregate welfare gain & -0.09 & -0.07 & 0.41 \\
\hline
\end{tabular}

I also compute the aggregate welfare effect of the reform to the economy assuming a utilitarian social welfare function in which a benevolent social planner assigns equal weight to all households in each country. The aggregate welfare gain is computed as the proportional increase in the consumption of all agents under status quo that makes the planner indifferent between remaining in the status quo (with the consumption increase) and implementing the tax reform. In this aggregate welfare measure, the percentage increase in consumption is the same for all agents within each country. More precisely, the aggregate welfare gain for a country is defined as $g^{A}$ that solves

$$
\int_{\left(a_{0}, \varepsilon_{0}\right)} E_{0} \sum_{t=0}^{\infty} \beta^{t} U\left(c_{t}^{N R}\left(1+g^{A}\right)\right) d \Gamma_{0}=\int_{\left(a_{0}, \varepsilon_{0}\right)} E_{0} \sum_{t=0}^{\infty} \beta^{t} U\left(c_{t}^{R}\right) d \Gamma_{0} .
$$

Table 4 panel (b) summarizes the results. Home has an aggregate welfare loss in both scenarios (0.09 and 0.07) and Foreign has a large welfare gain of 0.41 . While there is a greater majority in Home that potentially lose from the reform under financial integration than autarky, the aggregate welfare effect appears to be less severe under financial integration than under financial autarky, due to the smoothing effect on costs and benefits.

Discussion: Davila, Hong, Krusell, and Ríos-Rull (2012) study constrained efficiency where a utilitarian social planner in a standard heterogeneous agent-incomplete markets model chooses households' consumption and savings, subject to households' budget constraints. The solution to the planner's problem implies an aggregate asset level that is 
above the amount of assets accumulated in the decentralized economy. At the household level, the planner aims to redistribute income from the rich to the poor. Hence in a laissezfaire economy, this would imply lower interest rates and higher wages, causing a reduction in the income of wealthy households and an increase in the income of poor households that rely mostly on labor income. In such an environment, policies that increase wealth accumulation could be welfare enhancing. In the current analysis, the elimination of the capital income tax, induces changes that ultimately reduce Home wealth level with prices tilting against the poor. In contrast, the reform affects prices in favor of the poor and increases wealth to a level where the reform benefits the entire population.

The policy prescription to achieve constrained efficiency is to subsidize capital, rather than tax it. The current analysis does not consider capital income subsidies, but still has labor income subsidies financed by the Foreign government. This enables the Foreign residents, especially the wealth-poor, to accumulate more wealth over time, as labor income and wealth are positively correlated.

\subsection{Alternative scenarios}

I consider alternative model specifications and tax reforms to explore the desirability of capital income tax cuts further. In particular, I consider (i) reducing the Home capital income tax by about 5 percentage points, to 35\% in light of Aiyagari's (1994b) policy prescriptions, (ii) a simultaneous elimination of capital income taxes in both countries, (iii) an extension to the benchmark experiment that captures lower borrowing limits for households, and (iv) taxes on international bonds. Figures related to these experiments are presented in Appendix A2. One qualitative result common to these four experiments is that the reforms hurt the majority in Home, and benefit all households in Foreign.

\subsubsection{Aiyagari's long-run prescription: positive capital income taxes}

In Aiyagari (1994b), under the incomplete markets setting, a wide range of capital income tax rates from $25 \%$ to $45 \%$ appear to be optimal in the long run. Variations in the degree of risk aversion, labor supply elasticity, the pre-reform labor income tax rate, and the parameters of the earnings process contribute to these different results.

Domeij and Heathcote (2004) experiment with the closed economy model similar to the one studied in this paper, albeit with flat-rate labor income taxes, and find that moving above or below the current tax rate of $39.7 \%$ is undesirable, as the costs of the 
reform are shared by mostly wealth-poor households that constitute a large fraction of the population, whereas benefits are shared by the rich. The main takeaway from these closed economy analyses is that the optimal long-run capital income tax is positive, and yet it may be too costly to implement the optimal tax rate.

In this section, I analyze the welfare implications of Home's unilateral movement from a capital income tax rate of $39.7 \%$ to $35 \%$, the mid-point of $25 \%-45 \%$ as described by Aiyagari (1994b). The aim of the experiment is to find out whether a capital income tax rate that lies within the set of optimal taxes in the long run according to Aiyagari (1994b) is desirable under a less costly transition path in an open economy. The postreform dynamics are depicted in Appendix A.2, Section A.2.1.The welfare results are summarized in Table 6, panel (a). The experiment shows that there are initial gains in Home aggregate consumption, followed by a sharp decline. In line with this, the welfare analysis shows that moving to $35 \%$ is still undesirable for Home and desirable for Foreign - a result that appears to be unanimous in both countries. And this reform is much less desirable than the complete elimination of Home capital income taxes.

\subsubsection{Global elimination of capital income taxes}

The main experiment of a unilateral elimination of capital income tax by Home shows losses for the reforming country and gains for Foreign. The question addressed in this section is whether there are any incentives for countries to consider a cooperation in eliminating capital income taxes. In this section, I consider the bilateral elimination of capital income taxes, from $39.7 \%$ (Home) and $45 \%$ (Foreign), where average labor income taxation is altered as in the benchmark experiment. The dynamics are shown in Appendix A.2, Section A.2.2.

The reform implies a world-wide increase in efficiency in the long run, with greater long-run consumption, physical capital and output. The initial swings on the external accounts are determined by the relative size of these tax reforms as well as country sizes. More differently from the benchmark experiment, Home is able to generate more wealth after the reform as Foreign's increase in its own investment activity reduces the external resources for Home, which limits its long-run wealth transfer abroad but increases the short-run costs. The welfare results, as reported in Table 6, panel (b), show that the bilateral elimination of capital income taxes may find greater support in Home $14.4 \%$ benefit from the reform) compared to the unilateral elimination of the tax, but there is still no majority in Home that gain from the reform. The reform benefits all households 
in Foreign, due to sizable increases in after-tax labor income.

\subsubsection{Borrowing limits}

Interest rate increases bring welfare gains to households that are net lenders, and welfare costs to net borrowers. In a country with a 0 borrowing limit, all households gain from an increase in interest rates. On the other hand, having a tight borrowing constraint imposes limitations on the ability of consumption smoothing, which reduces welfare. To assess the potential effects on welfare, I relax the assumption that households cannot borrow. In fact, according to $2007 \mathrm{SCF}, 24 \%$ of US households hold negative or zero financial assets. Targeting this ratio, I set the Home borrowing limit at $\underline{a}=-0.39$. Interpreting these limits is the degree of financial deepness as in Mendoza, Quadrini, and Rios-Rull (2007) and considering that the OECD countries are not very heterogenous in terms of their financial development levels, I assume the same borrowing limit for Foreign, and hence let $\underline{a}^{*}=-0.39$.

The post-reform dynamics are depicted in Appendix A.2, Section A.2.3 and welfare results are summarized in Table 6, panel c. Under lower borrowing limits, the results of the elimination of capital income taxes in Home appear to be more favorable than the benchmark experiment, but the majority still do not gain from the reform (only 5.3\%). The aggregate consumption equivalent welfare gains are -0.07 and 0.41 for Home and Foreign, respectively.

\subsubsection{Bond taxes}

In a more realistic scenario especially for advanced countries, I relax the assumption that the interest income on internationally traded bonds is not taxed. Following Mendoza and Tesar (1998), I assume that these assets are taxed on a rate equal to the Home capital income tax, $\tau^{b}=\tau^{k}$. Under the residence principle and perfect mobility of private bonds, it follows that both countries must tax foreign income at equal rates, i.e., $\tau^{b}=\tau^{b *}$. Hence with financial integration, no arbitrage implies that after tax interest income in private bonds, government bonds and physical capital in Home must be equalized as follows (can be stated similarly for Foreign).

$$
r_{t}\left(1-\tau^{b}\right)=r_{t}^{d}\left(1-\tau^{k}\right)=\left(r_{t}^{k}-\delta\right)\left(1-\tau^{k}\right)
$$

As a policy experiment, I consider the unilateral elimination of Home capital income 
tax, $\tau^{k}$, while keeping the bond taxes at $\tau^{b}$ and $\tau^{b *}$ at $39.7 \%$. The quantitative experiment suggests that since the incentives for international borrowing and lending are distorted with bond taxes, the reform becomes more costly to be financed via international borrowing, making it less desirable for Home than the case without. These results are shown in Table 6, panel c.

Table 6: Welfare implications of tax reform (alternative scenarios)

\begin{tabular}{|c|c|c|c|c|}
\hline & \multicolumn{2}{|c|}{$\begin{array}{c}\text { (a) Aiyagari's long-run } \\
\text { prescription }\end{array}$} & \multicolumn{2}{|c|}{$\begin{array}{c}\text { (b) Global elimination of } \\
\text { capital taxes }\end{array}$} \\
\hline & Home & Foreign & Home & Foreign \\
\hline Fraction in favor $(100 \%)$ & $0.1 \%$ & $100 \%$ & $14.4 \%$ & $100 \%$ \\
\hline High $(4.5 \%)$ & $0.5 \%$ & $100 \%$ & $48.4 \%$ & $100 \%$ \\
\hline Medium (91\%) & $0.1 \%$ & $100 \%$ & $12.9 \%$ & $100 \%$ \\
\hline Low $(4.5 \%)$ & $0.0 \%$ & $100 \%$ & $0.9 \%$ & $100 \%$ \\
\hline \multirow[t]{2}{*}{ Aggregate welfare gain } & -0.08 & 0.41 & -0.08 & 0.42 \\
\hline & (c) $\mathrm{Lo}$ & $\begin{array}{l}\text { borrowing } \\
\text { iits }\end{array}$ & \multicolumn{2}{|c|}{$\begin{array}{c}\text { (d) Taxes on private } \\
\text { bonds }\end{array}$} \\
\hline (c) & Home & Foreign & Home & Foreign \\
\hline Fraction in favor $(100 \%)$ & $5.3 \%$ & $100 \%$ & $2.2 \%$ & $100 \%$ \\
\hline $\operatorname{High}(4.5 \%)$ & $16.7 \%$ & $100 \%$ & $8.2 \%$ & $100 \%$ \\
\hline Medium (91\%) & $4.8 \%$ & $100 \%$ & $2.0 \%$ & $100 \%$ \\
\hline Low $(4.5 \%)$ & $3.9 \%$ & $100 \%$ & $1.5 \%$ & $100 \%$ \\
\hline Aggregate welfare gain & -0.07 & 0.41 & -0.10 & 0.41 \\
\hline
\end{tabular}

\section{Conclusion}

In this paper, I investigate the implications of eliminating (or reducing) capital income taxes in a two-country heterogenous agent incomplete markets model, calibrated to match the US and rest of the OECD. The positive results from the experiment are that after the unilateral elimination of the capital income tax Home, the reform induces transfers of wealth within the country, as well as across countries due to movements in after-tax 
interest rates, labor income, and government's response to alter the average labor income taxation and inclination to issue debt.

The movements in the world interest rate and after-tax labor income exhibit both qualitatively and quantitatively different patterns than those in the closed-economy version of this experiment. This is due to a large capital accumulation by the reforming country to the extent that it has the ability to borrow from the rest of the world. In an open economy, even though the after-tax interest rate initially rises, its eventual decline relative to the initial steady state implies lower returns to household's assets, which in turn lowers the gains from the reform. In the closed economy, the interest rate has a more favorable path. After-tax wages go up due to greater capital accumulation in the open economy, whereas they fall under financial autarky. The quantitative experiments suggest that for most households in these reforming model economies, the reform is very much costly. A normative result from these experiments is that the capital income tax should not be eliminated.

The reform has positive spillover effects to the rest of the world - and these are quantitatively large welfare effects. Foreign government's ability to subsidize the labor income of the majority of households, along with international wealth transfers, help the nation accumulate more wealth over time. The nexus between wealth changes and welfare implications of the reform appear to be closely linked to the notion of constrained-efficient allocations studied by Dávila, Hong, Krusell, and Ríos-Rull (2012).

Accordingly, the laissez faire allocation of wealth in a model which captures a distribution of households that mostly rely on labor income is much lower than the planner's allocation under constrained efficiency. In the initial steady state where both countries have capital income taxes, the allocation of wealth might already be suboptimal based on the definition of constrained efficiency. After the elimination of capital income tax, Home increases its physical capital and government debt, while it transfers a much larger amount of external wealth to Foreign as the world interest rate falls during transition. Hence, the reform carries Home further away from the constrained-efficient allocation of wealth. In turn, it can be argued that as Foreign's wealth level goes up, it reaches a level closer to that implied by constrained-efficiency. 


\section{References}

[1] Ábraham, Á. and Cárceles-Poveda, E., 2010. Endogenous trading constraints with incomplete asset markets. Journal of Economic Theory, 145(3), pp.974-1004.

[2] Aiyagari, S.R., 1994a. Uninsured idiosyncratic risk and aggregate saving. The Quarterly Journal of Economics, 109(3), pp.659-684.

[3] Aiyagari, S. R. 1994b. Optimal capital income taxation with incomplete markets, borrowing constraints, and constant discounting. Working Paper No. 508,.Federal Reserve Bank of Minneapolis.

[4] Aiyagari, S.R., 1995. Optimal capital income taxation with incomplete markets, borrowing constraints, and constant discounting. Journal of Political Economy, 103(6), pp.1158-1175.

[5] Aiyagari, S.R. and McGrattan, E.R., 1998. The optimum quantity of debt. Journal of Monetary Economics, 42(3), pp.447-469.

[6] Azzimonti, M., De Francisco, E. and Quadrini, V., 2014. Financial globalization, inequality, and the rising public debt. American Economic Review, 104(8), pp.22672302.

[7] Bewley, T., 1986. Stationary monetary equilibrium with a continuum of independently fluctuating consumers. Contributions to mathematical economics in honor of Gérard Debreu, 79.

[8] Carroll, C.D., 2006. The method of endogenous gridpoints for solving dynamic stochastic optimization problems. Economics letters, 91(3), pp.312-320.

[9] Chamley, C., 1986. Optimal taxation of capital income in general equilibrium with infinite lives. Econometrica: Journal of the Econometric Society, pp.607-622.

[10] Chang, B.H., Chang, Y. and Kim, S.B., 2016. Pareto Weights in Practice: A Quantitative Analysis Across 32 OECD Countries. Mimeo.

[11] Chen, K., İmrohoroğlu, A. and İmrohoroğlu, S., 2009. A quantitative assessment of the decline in the US current account. Journal of Monetary Economics, 56(8), pp.1135-1147. 
[12] Coleman, W.J., 1990. Solving the stochastic growth model by policy-function iteration. Journal of Business \& Economic Statistics, 8(1), pp.27-29.

[13] Conesa, J.C., Kitao, S. and Krueger, D., 2009. Taxing capital? Not a bad idea after all! American Economic Review, 99(1), pp.25-48.

[14] Davies, J., Lluberas, R. and Shorrocks, A., 2012. Credit Suisse global wealth databook. Zurich: Credit Suisse Research Institute.

[15] Davila, J., Hong, J.H., Krusell, P. and Ríos-Rull, J.V., 2012. Constrained efficiency in the neoclassical growth model with uninsurable idiosyncratic shocks. Econometrica, 80(6), pp.2431-2467.

[16] Domeij, D. and Heathcote, J., 2004. On the distributional effects of reducing capital taxes. International Economic Review, 45(2), pp.523-554.

[17] Guerrieri, V. and Lorenzoni, G., 2011. Credit crises, precautionary savings, and the liquidity trap. The Quarterly Journal of Economics.

[18] Heathcote, J., Storesletten, K. and Violante, G.L., 2014. Optimal tax progressivity: An analytical framework (No. w19899). National Bureau of Economic Research.

[19] Huggett, M., 1993. The risk-free rate in heterogeneous-agent incomplete-insurance economies. Journal of Economic Dynamics and Control, 17(5), pp.953-969.

[20] İmrohoroğlu, A., 1989. Cost of business cycles with indivisibilities and liquidity constraints. Journal of Political Economy, 97(6), pp.1364-1383.

[21] İmrohoroğlu, S., 1998. A quantitative analysis of capital income taxation. International Economic Review, pp.307-328.

[22] Judd, K.L., 1985. Redistributive taxation in a simple perfect foresight model. Journal of Public Economics, 28(1), pp.59-83.

[23] Kabukçuoğlu, A. and Martínez-García, E., 2016. The market resources method for solving dynamic optimization problems. (No. w275) Federal Reserve Bank of Dallas. Globalization and Monetary Policy Institute.

[24] Klein, P., Quadrini, V. and Rios-Rull, J.V., 2005. Optimal time-consistent taxation with international mobility of capital. Advances in Macroeconomics, 5(1). 
[25] Landry, A.E., 2011. How the US tax system stacks up against other G-7 economies. Economic Letter, 6. Federal Reserve Bank of Dallas.

[26] Lucas Jr, R.E., 1990. Supply-side economics: An analytical review. Oxford Economic Papers, 42(2), pp.293-316.

[27] Mendoza, E.G. and Tesar, L.L., 1998. The international ramifications of tax reforms: supply-side economics in a global economy. American Economic Review, pp.226-245.

[28] Mendoza, E.G. and Tesar, L.L., 2005. Why hasn't tax competition triggered a race to the bottom? Some quantitative lessons from the EU. Journal of Monetary Economics, 52(1), pp.163-204.

[29] Mendoza, E.G., Tesar, L.L. and Zhang, J., 2014. Saving Europe?: The unpleasant arithmetic of fiscal austerity in integrated economies (No. w20200). National Bureau of Economic Research.

[30] Mendoza, E.G., Quadrini, V. and Ríos-Rull, J.V., 2007. On the Welfare Implications of Financial Globalization without Financial Development (No. w13412). National Bureau of Economic Research.

[31] Mendoza, E.G., Quadrini, V. and Rios-Rull, J.V., 2009. Financial integration, financial development, and global imbalances. Journal of Political Economy, 117(3), pp.371-416.

[32] Quadrini, V., 2005. Policy commitment and the welfare gains from capital market liberalization. European Economic Review, 49(8), pp.1927-1951.

[33] Rendahl, P., 2015. Inequality Constraints and Euler Equation-based Solution Methods. The Economic Journal, 125(585), pp.1110-1135.

[34] Röhrs, S. and C. Winter. 2011. "Wealth Inequality and the Optimal Level of Government Debt." Mimeo. 


\section{A Appendix}

\section{A.1 Computational Algorithm}

\section{A.1.1 Pre-reform steady state:}

I provide the algorithm for the case with inelastic labor supply.

1. Create grids on next period's assets and this period's shocks, $\left(a^{\prime}, \varepsilon\right)$. Define $a^{\prime} \epsilon A=$ $\left\{a_{1}, a_{2}, \ldots, a_{N}\right\}$ where $a_{1}$ is the borrowing limit in each country; and define the productivity shocks so that. $\varepsilon \epsilon E=\left\{\varepsilon_{1, \ldots}, \varepsilon_{M}\right\}$.

2. Make a guess on the world interest rate, $r$. Notice that $r \in(0,1 / \beta-1)$. Set values for $D_{0}$ and $D_{0}^{*}$. Given the tax rates, compute the implied $K / N$ ratio and remaining factor prices for both countries: $r^{k}, r^{k *}, w$ and $w^{*}$.

3. Make a guess for the initial cumulative distribution of households over assets and shocks, $\Gamma_{0}\left(a^{\prime}, \varepsilon\right)$. A uniform distribution function is a good guess.

4. Make an initial guess on tomorrow's consumption policy function, $c_{0}\left(a^{\prime}, \varepsilon\right)$. A good guess can be based on the budget constraint.

5. Construct the right hand side of the Euler equation, for all pairs of $\left(a^{\prime}, \varepsilon\right) \epsilon A \times E$, and solve or today's consumption function algebraically, i.e. find $\tilde{c}$ that solves

$$
U_{c}(\tilde{c})=\beta(1+r) \sum_{\varepsilon^{\prime} \in E} \Pi\left(\varepsilon^{\prime} \mid \varepsilon\right) U_{c}\left(c_{0}\left(a^{\prime}, \varepsilon\right)\right)
$$

6. Using the budget constraint, compute today's asset holdings $\bar{a}\left(a^{\prime}, \varepsilon\right)$ such that

$$
\bar{a}\left(a^{\prime}, \varepsilon\right)=\left[\tilde{c}+a^{\prime}-N w\left(1-\tau^{n}\right) \varepsilon\right] /(1+r)
$$

Hence, we find today's assets given tomorrow's asset holding is $a^{\prime}$ and today's productivity shock is $\varepsilon$. Notice that $\bar{a}\left(a^{\prime}, \varepsilon\right)$ is not necessarily on the grids defined in $A$, that is, the grids we find now are endogenous grid points. Update the initial guess for consumption as follows.

a. If $\bar{a}\left(a^{\prime}, \varepsilon\right)$ causes the borrowing constraint to bind next period, compute the new guess $\tilde{c}_{0}\left(a^{\prime}, \varepsilon\right)$ using piecewise linear interpolation on the closest grid points $a_{i}$ and $a_{j}$ such that, $a_{i}<\bar{a}\left(a^{\prime}, \varepsilon\right)<a_{j}$ and using consumption rules at $c_{0}\left(a_{i}, \varepsilon\right)$ and $c_{0}\left(a_{j}, \varepsilon\right)$. 
b. If $\bar{a}\left(a^{\prime}, \varepsilon\right)$ causes the borrowing constraint not to bind next period, then set $\tilde{c}_{0}\left(a^{\prime}, \varepsilon\right)$ $=\tilde{c}$ from step 6 .

7. Check convergence for any asset grid and productivity shock, based on the metric

$$
\max \left\{\left|\tilde{c}_{0}\left(a^{\prime}, \varepsilon\right)-c_{0}\left(a^{\prime}, \varepsilon\right)\right|\right\}<\varepsilon
$$

where $\varepsilon$ is a small number. If convergence is not achieved, go to step 5 .

8. Given the initial guess for distribution, $\Gamma_{0}\left(a^{\prime}, \varepsilon\right)$, interpolate on grid points $a_{i}$ and $a_{j}$ to find the distribution over the endogenous grid points, $\left.\Gamma\left(h_{a}^{-1}\left(a^{\prime}, \varepsilon\right)\right), \varepsilon\right)$. The inverse of the policy functions is already calculated in an earlier step. Hence $h_{a}^{-1}\left(a_{t+1}, \varepsilon_{t}\right)=$ $\bar{a}\left(a^{\prime}, \varepsilon\right)$. Then using the Markov transition matrix, find tomorrow's distribution

$$
\Gamma\left(a^{\prime}, \varepsilon^{\prime}\right)=\sum_{\varepsilon} \Pi\left(\varepsilon^{\prime} \mid \varepsilon\right) \Gamma\left(\bar{a}\left(a^{\prime}, \varepsilon\right), \varepsilon\right)
$$

Construct a metric as in step 8 to check convergence.

9. Repeat these steps for two countries, compute aggregate savings and check whether global asset market clears. Update the interest rate, $r$ using bisection method.

10. Calculate the output level, and then the public debt level from the public debt-toGDP ratio that is targeted. Then calculate the implied government expenditure, G.

\section{A.1.2 Transition and post-reform steady state:}

1. Set $T$, the number of periods to converge to the new steady state.

2. Pick a new value for $\tau^{k}$. The new tax rate is imposed before the decisions are made in period 1 .

3. Make a guess for the path of Home capital stock, $\left\{K_{t}\right\}_{t=2}^{T-1}$. Compute the implied path for the interest rate. Then $\left\{K_{t}^{*}\right\}_{t=2}^{T-1}$ can be obtained. Calculate wages.

4. Using the government budget constraint for all periods, and for given values of $D_{0}$ and $G$, find the new implied labor income tax parameter, $\tau^{n}$. (One also needs to assume that $D_{T}=D_{T-1}$ as in Domeij and Heathcote (2004)). 
5. Having found $\tau^{n}$, find the sequence of government debt, $\left\{D_{t}\right\}_{t=2}^{T}$. Repeat this for Foreign.

6. Calculate the post-reform steady state, similar to the pre-reform steady state.

7. For both countries, solve for the household's optimization problem along the transition path, starting from the final steady state going backwards. Application of the endogenous grid point method is similar to the description in the pre-reform steady state above. Find the consumption rules back until period 1. Find the implied asset holdings, and the post-tax household distribution over assets and productivity shocks at period 1 .

8. Then update the distributions forward, using the Markov transition matrix and households' optimal saving decisions. Do the aggregations, compute the implied sequence of capital stock $\left\{\tilde{K}_{t}\right\}_{t=2}^{T-1}$ for Home using $\tilde{K}_{t}=A_{t}-D_{t}+A_{t}^{*}-K_{t}^{*}-D_{t}^{*}$.

9. Check whether the initial path of capital stock has converged to the implied series. If so, check whether $T$ is sufficiently large or not. 


\section{A.2 Macroeconomic dynamics in alternative tax reforms}

\section{A.2.1 Aiyagari's long-run prescription: positive capital income taxes}
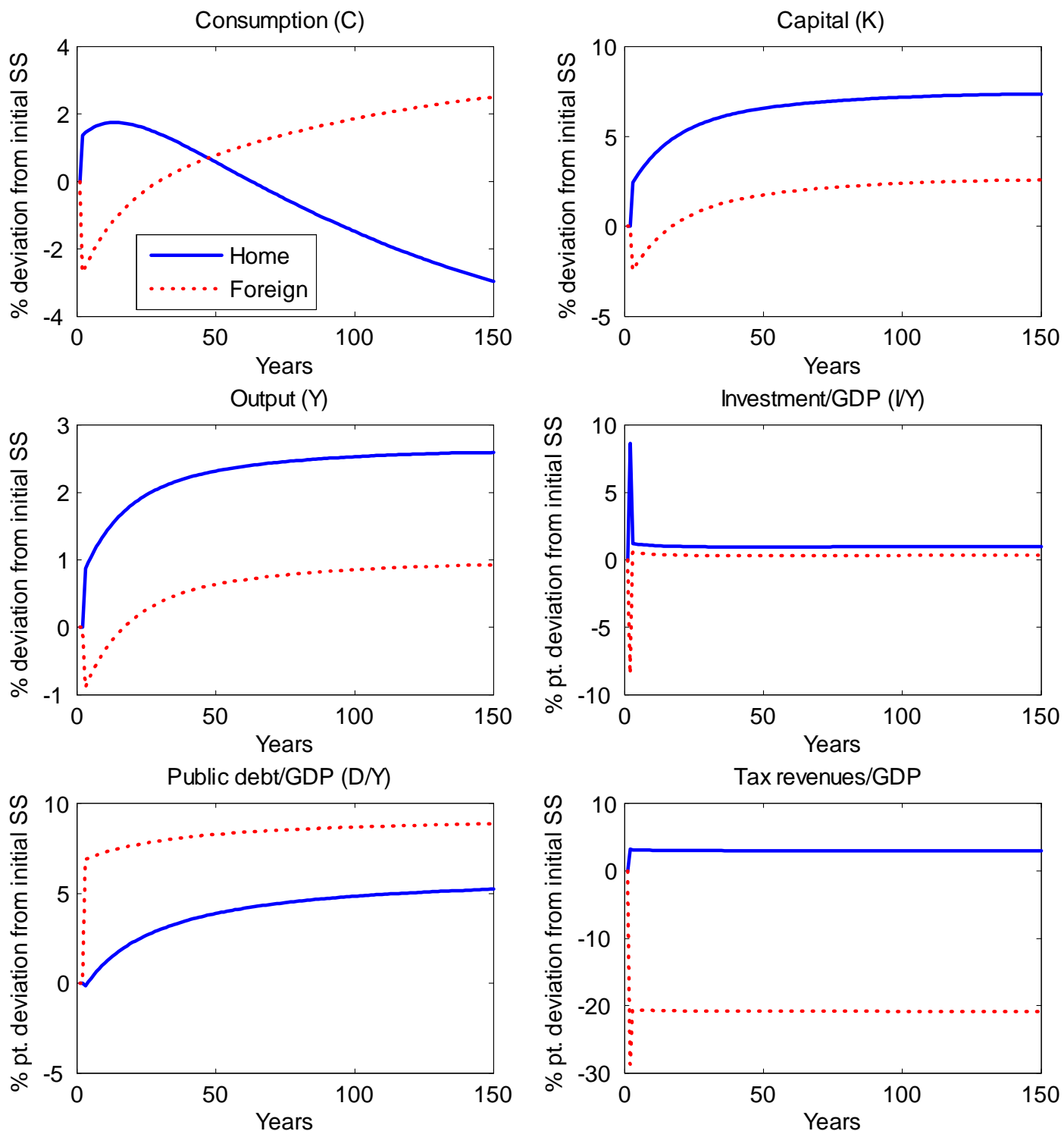

Figure A1a: Dynamics after a Home capital income tax cut from $39.7 \%$ to $35 \%$. 

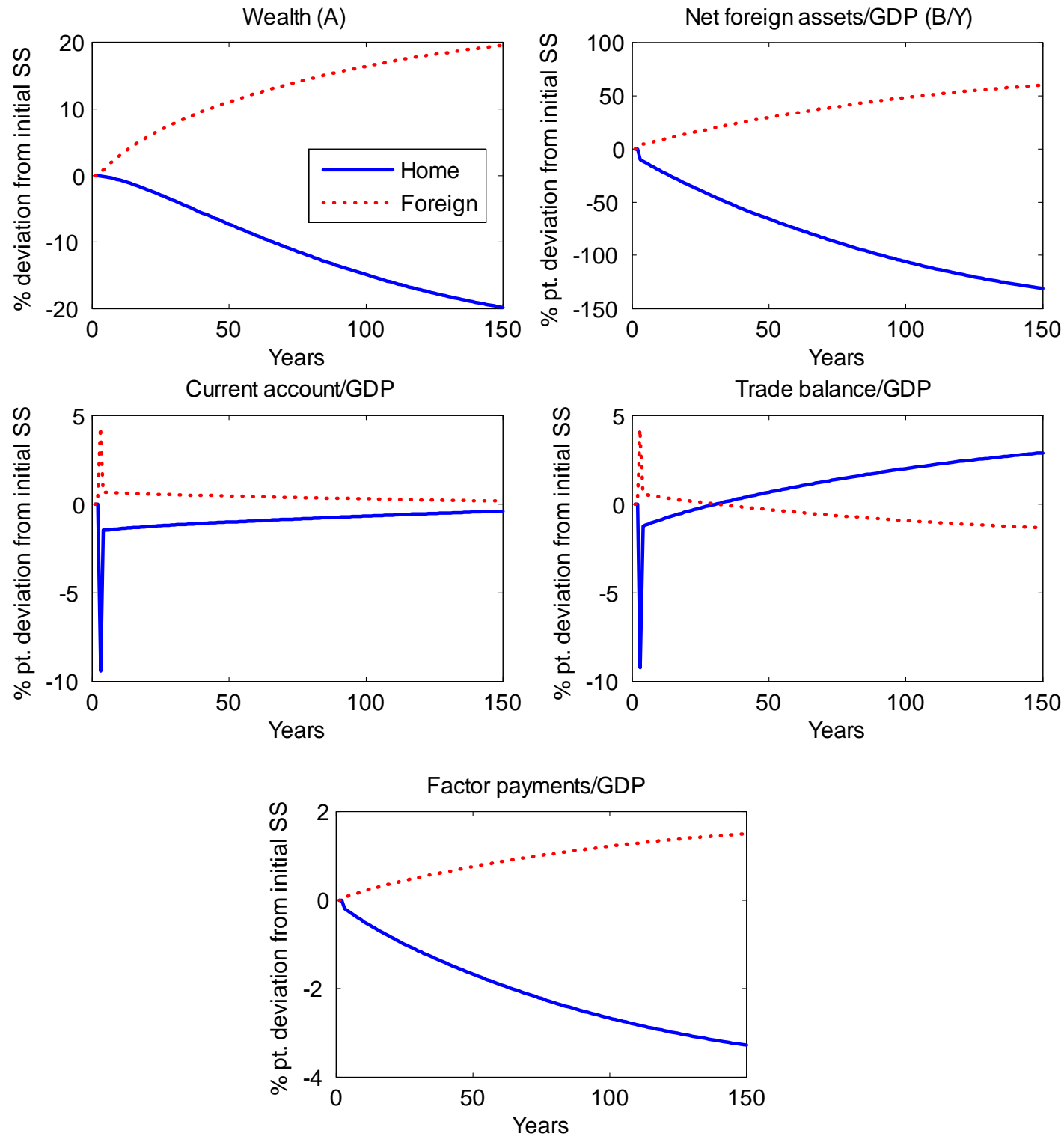

Figure A1b: Dynamics after a Home capital income tax cut from $39.7 \%$ to $35 \%$. 

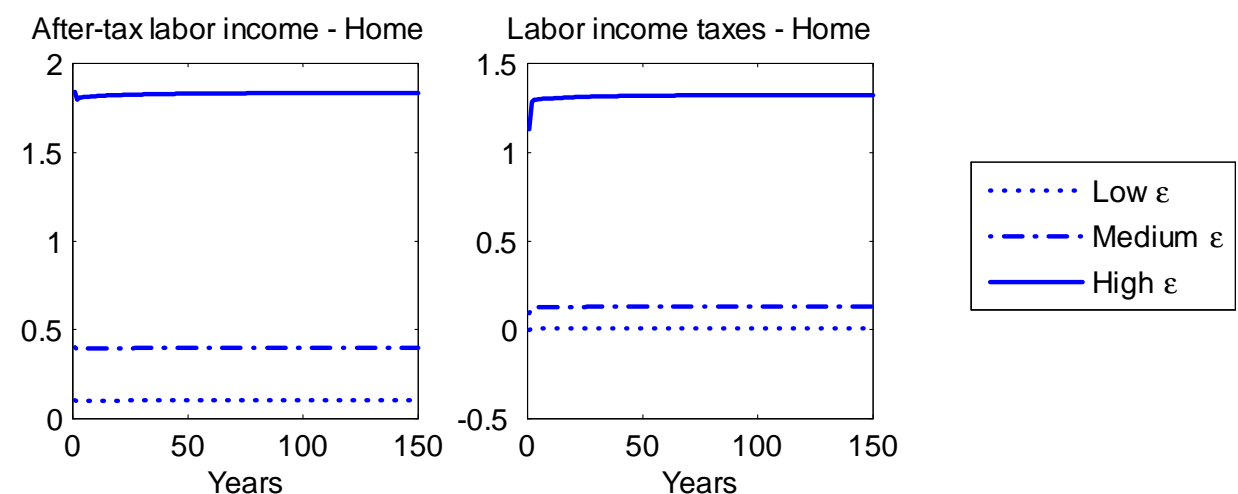

After-tax labor income - Foreign

Labor income taxes - Foreign
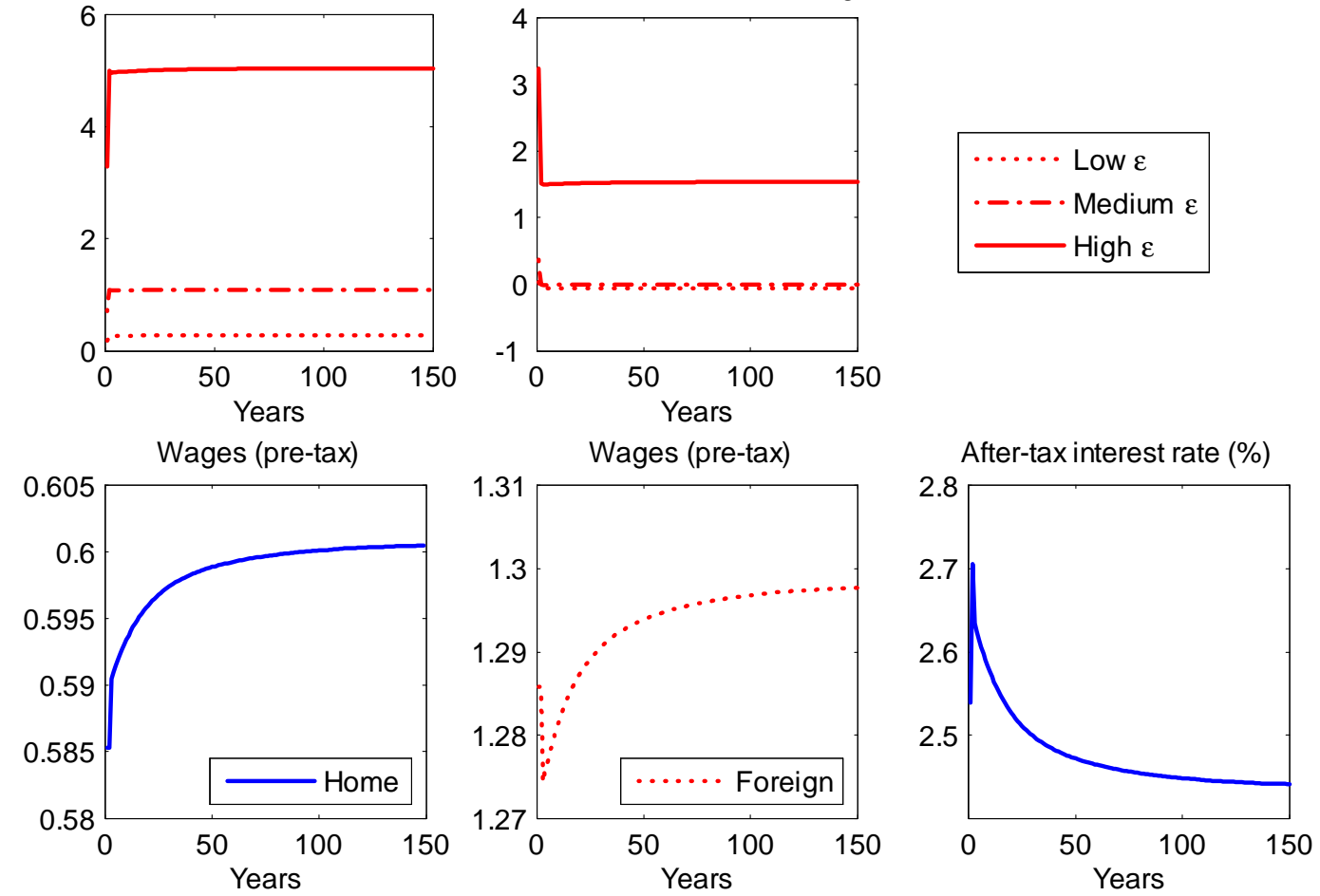

Figure A1c: Dynamics after a Home capital income tax cut from $39.7 \%$ to $35 \%$. 


\section{A.2.2 Global elimination of capital income taxes}
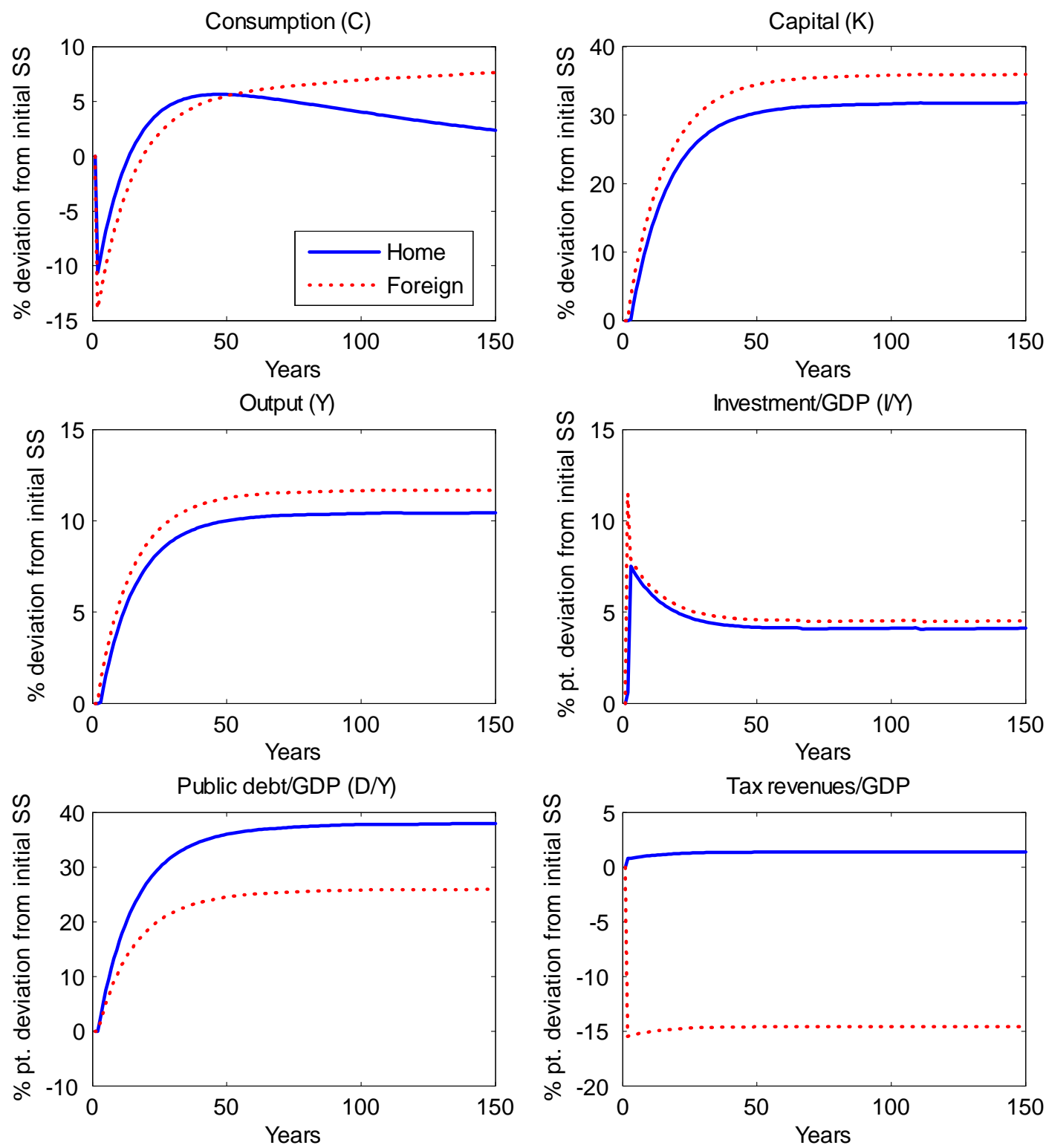

Figure A2a: Dynamics after global elimination of capital income taxes (From 39.7\% in Home and $45 \%$ in Foreign) 

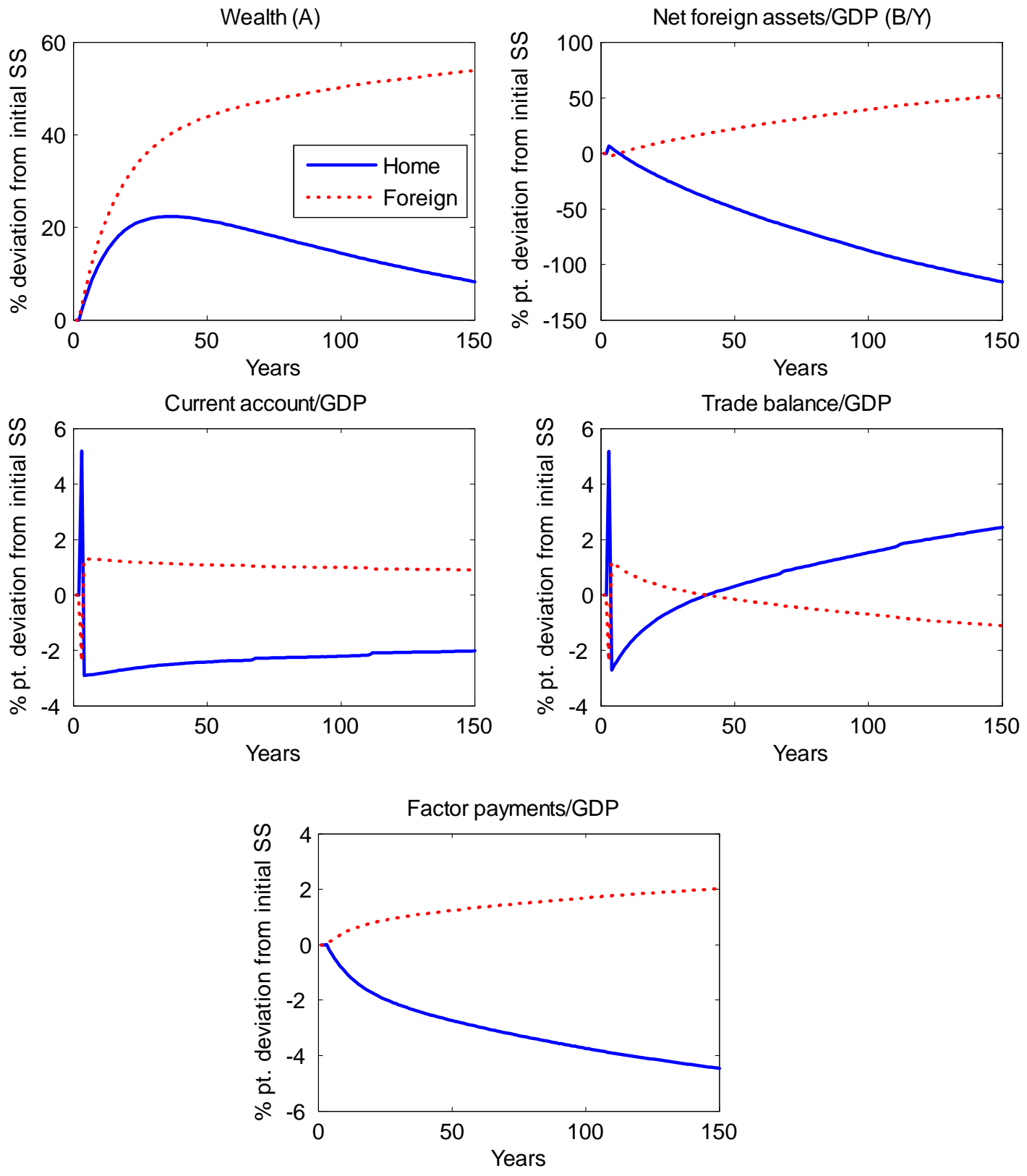

Figure A2b: Dynamics after global elimination of capital income taxes (From 39.7\% in Home and $45 \%$ in Foreign) 

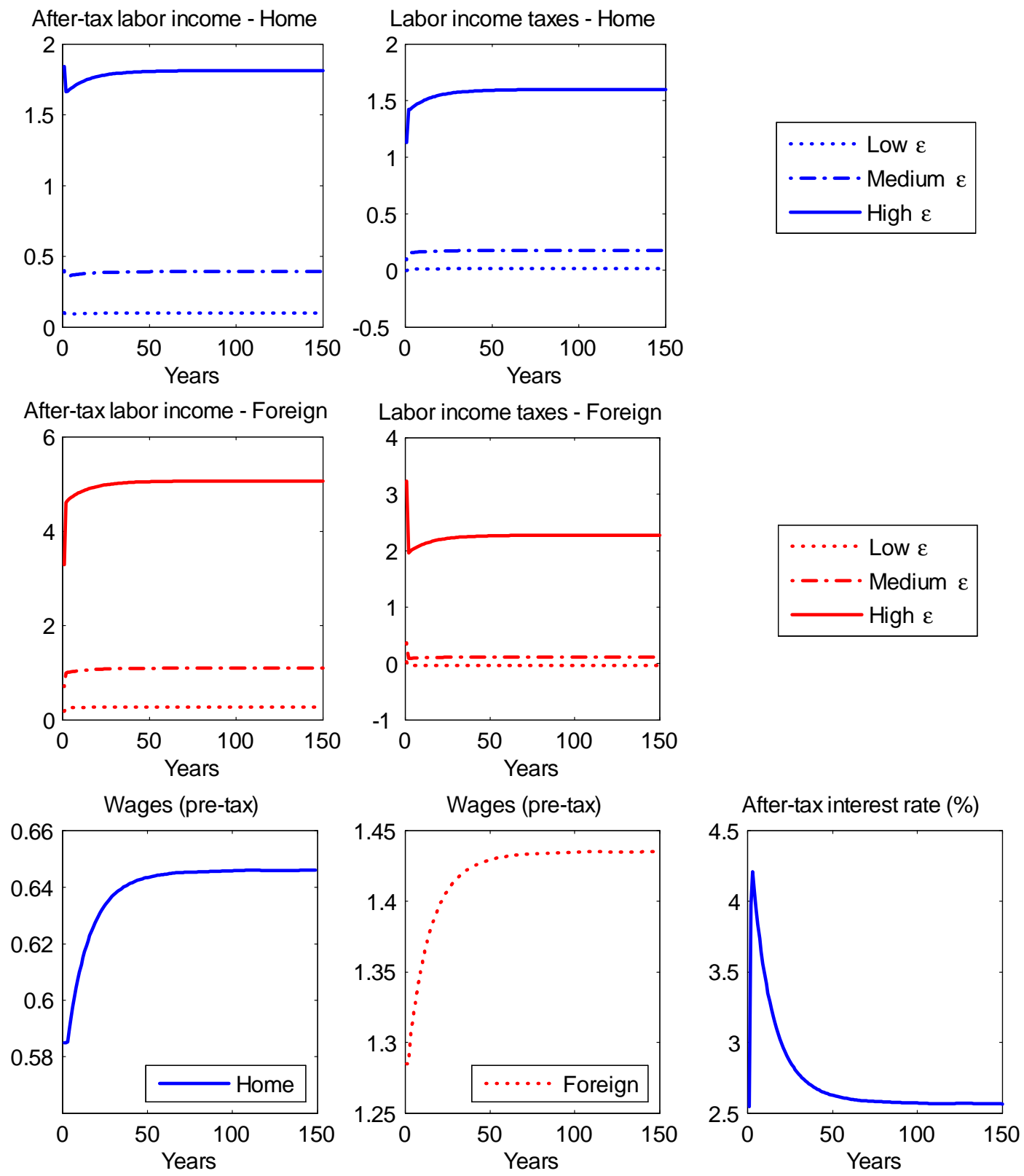

Figure A2c: Dynamics after global elimination of capital income taxes (From 39.7\% in Home and $45 \%$ in Foreign) 


\section{A.2.3 Borrowing limits}
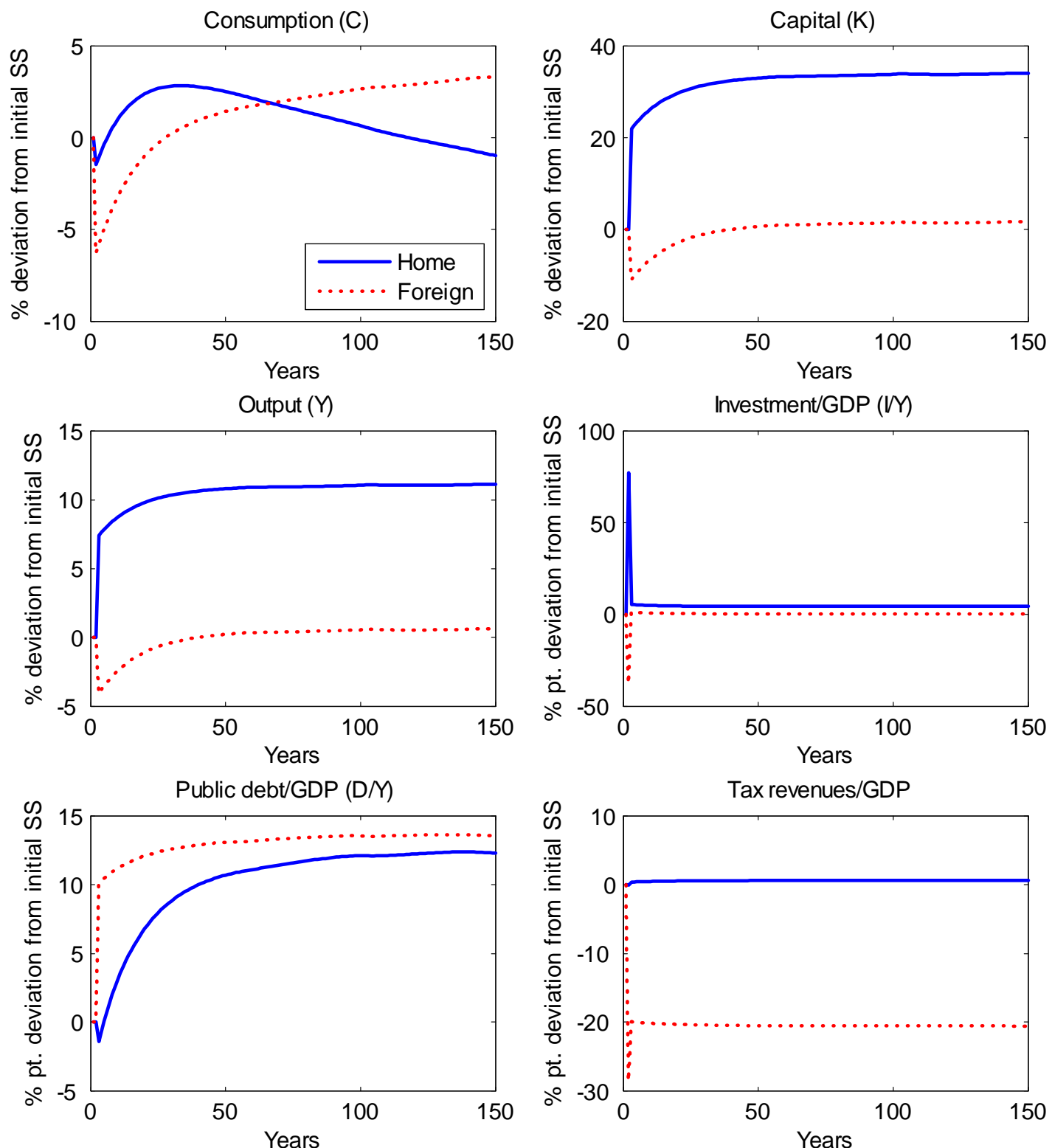

Figure A3a: Dynamics after the elimination of Home capital income taxes with negative borrowing limits $(\underline{a}=-0.39)$. 

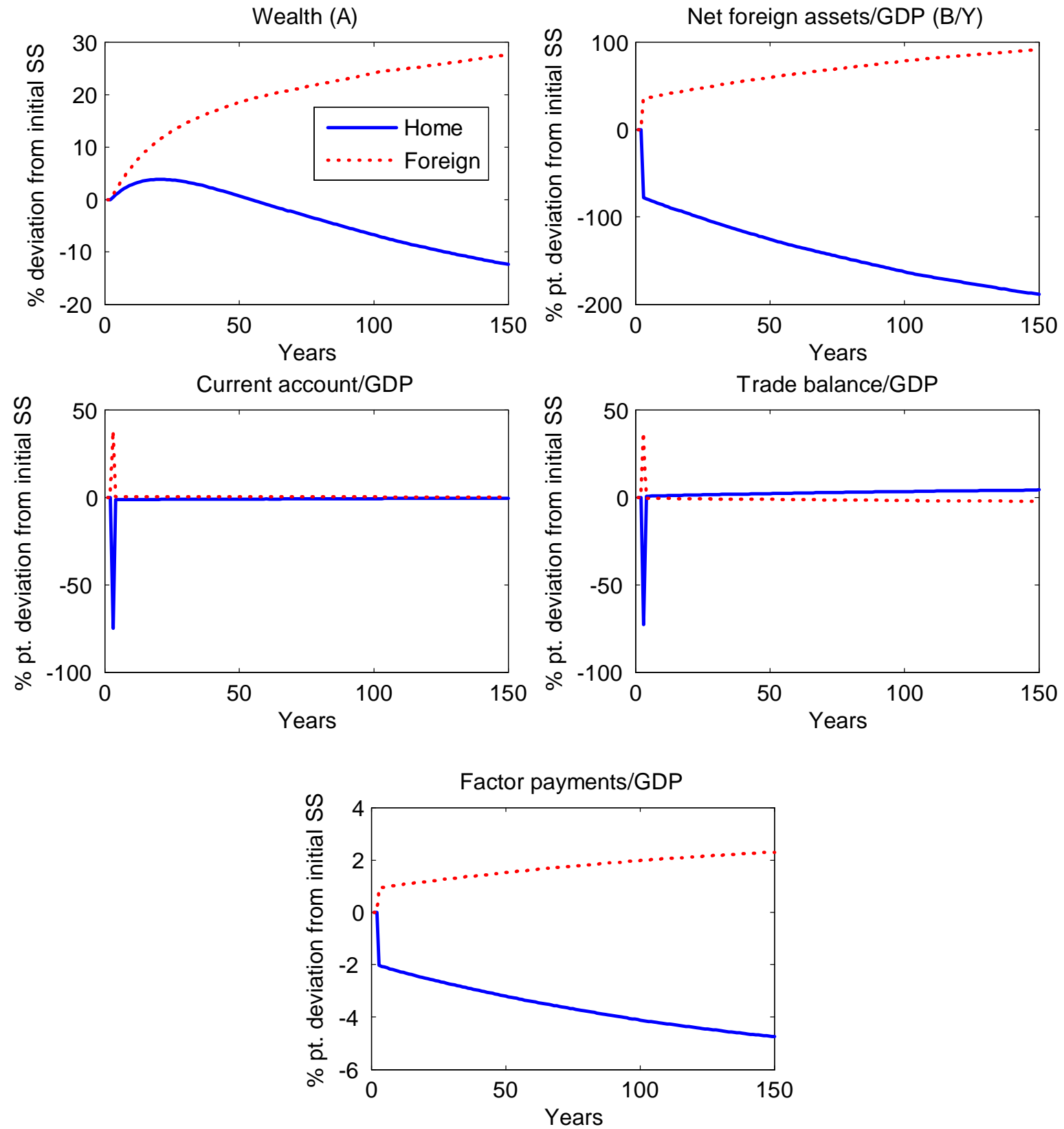

Figure A3b: Dynamics after the elimination of Home capital income taxes with negative borrowing limits $(\underline{a}=-0.39)$. 

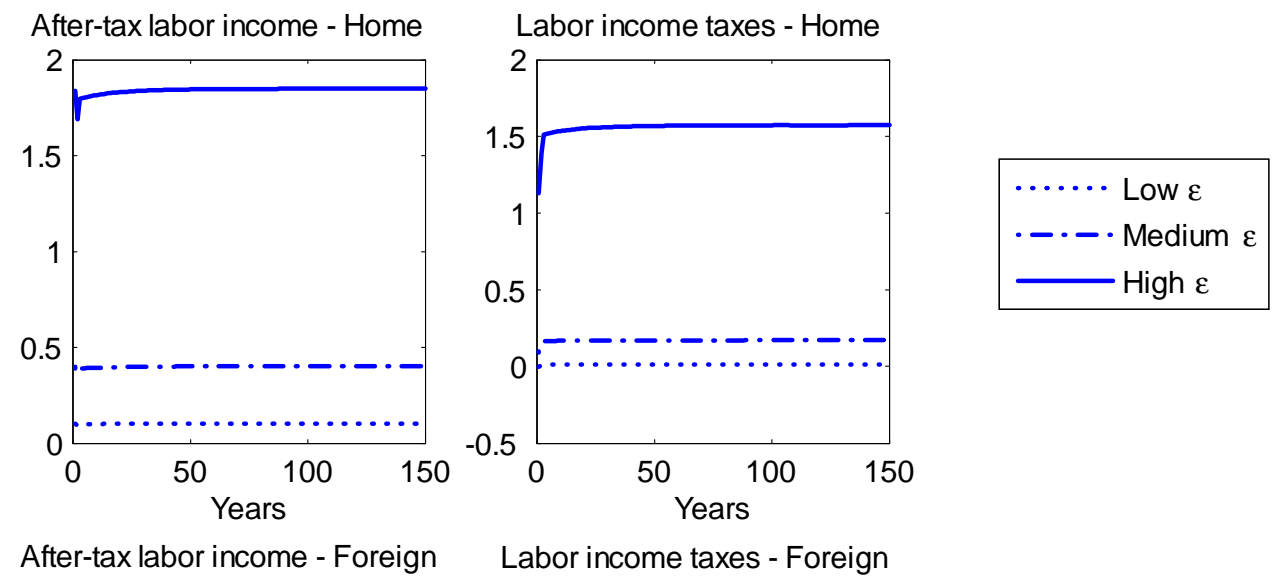

Labor income taxes - Foreign
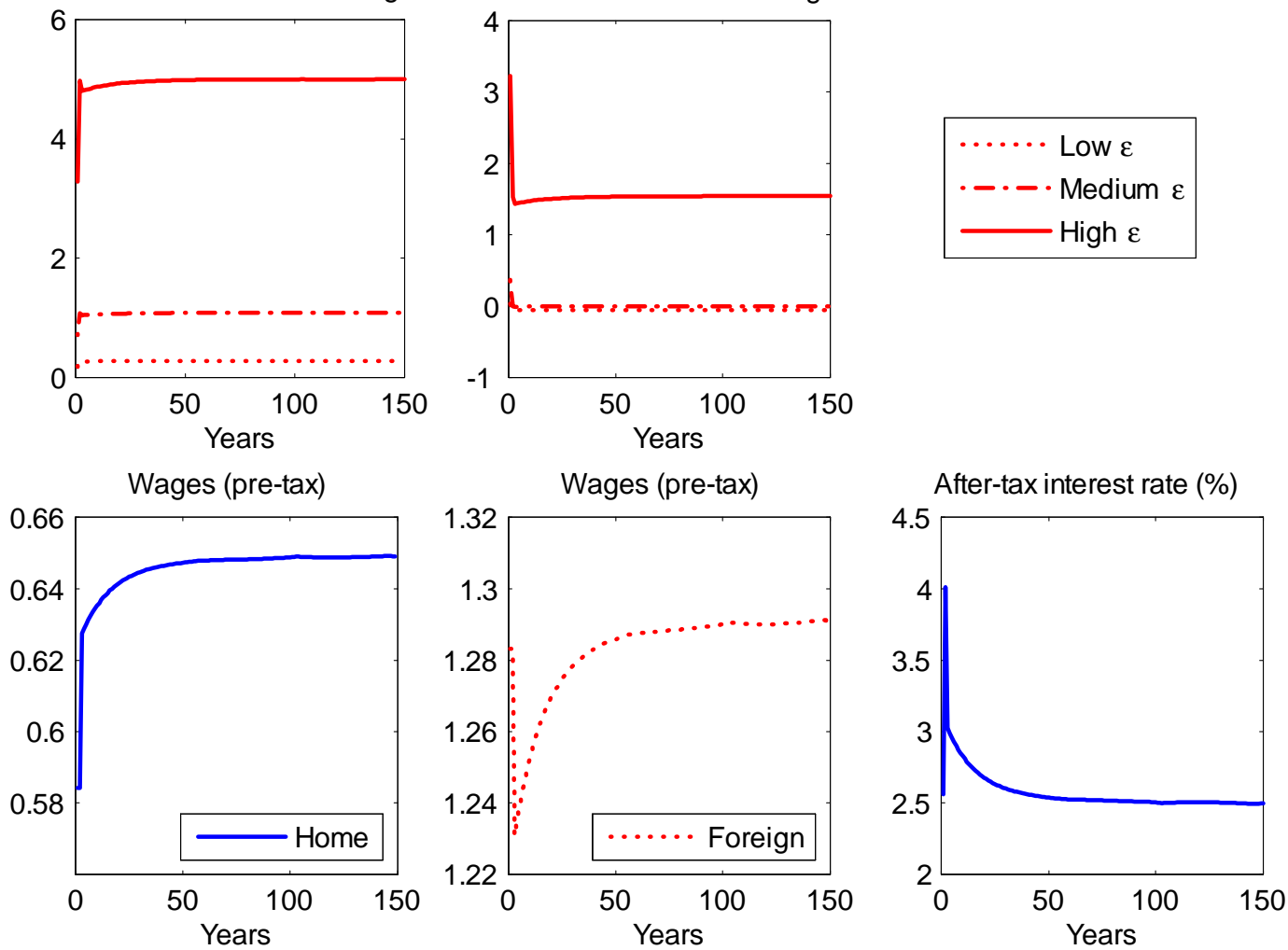

Figure A3c: Dynamics after the elimination of Home capital income taxes with negative borrowing limits $(\underline{a}=-0.39)$. 


\section{A.2.4 Bond taxes}
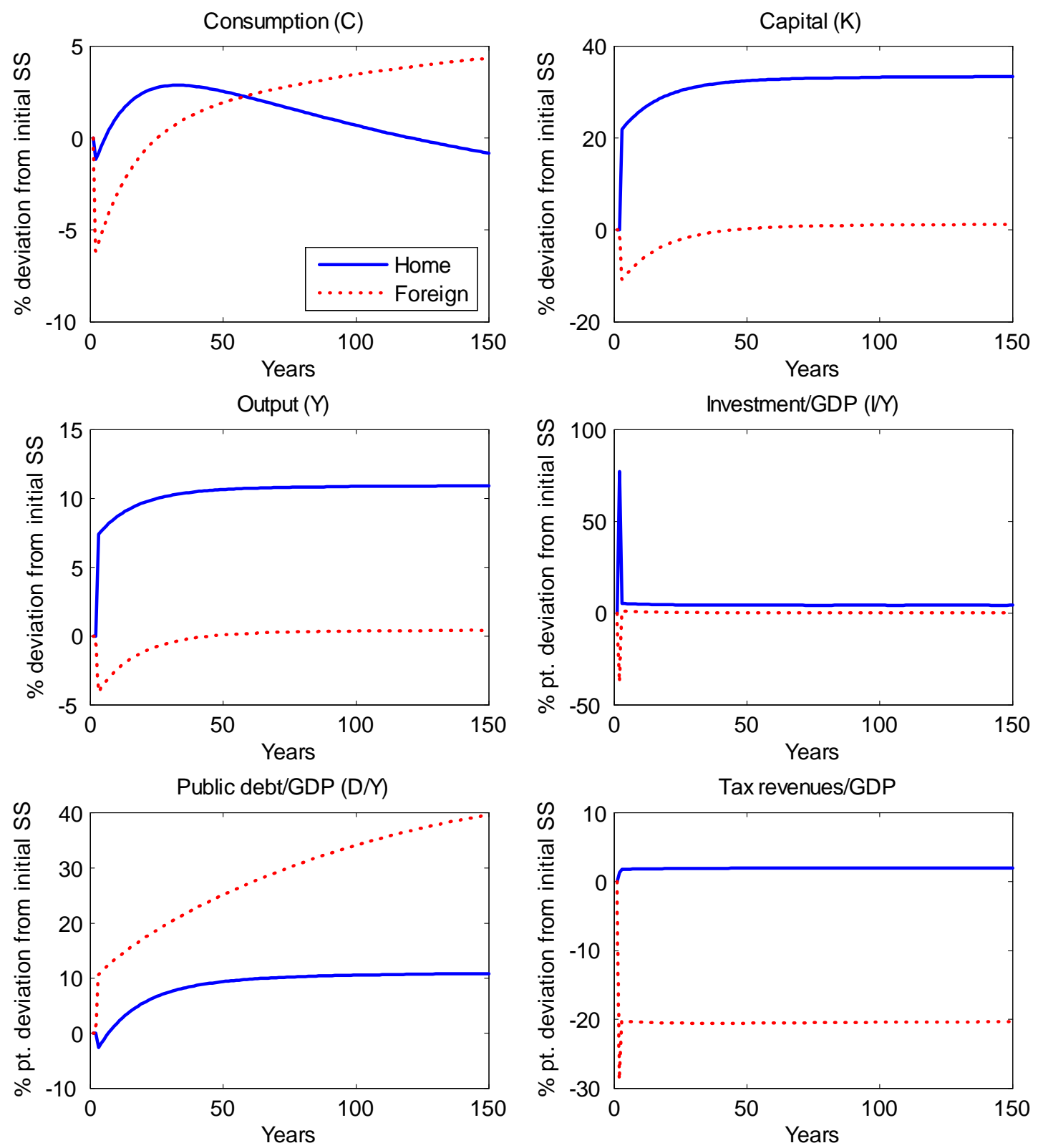

Figure A4a: Dynamics after the elimination of Home capital income tax with taxes on private bonds 

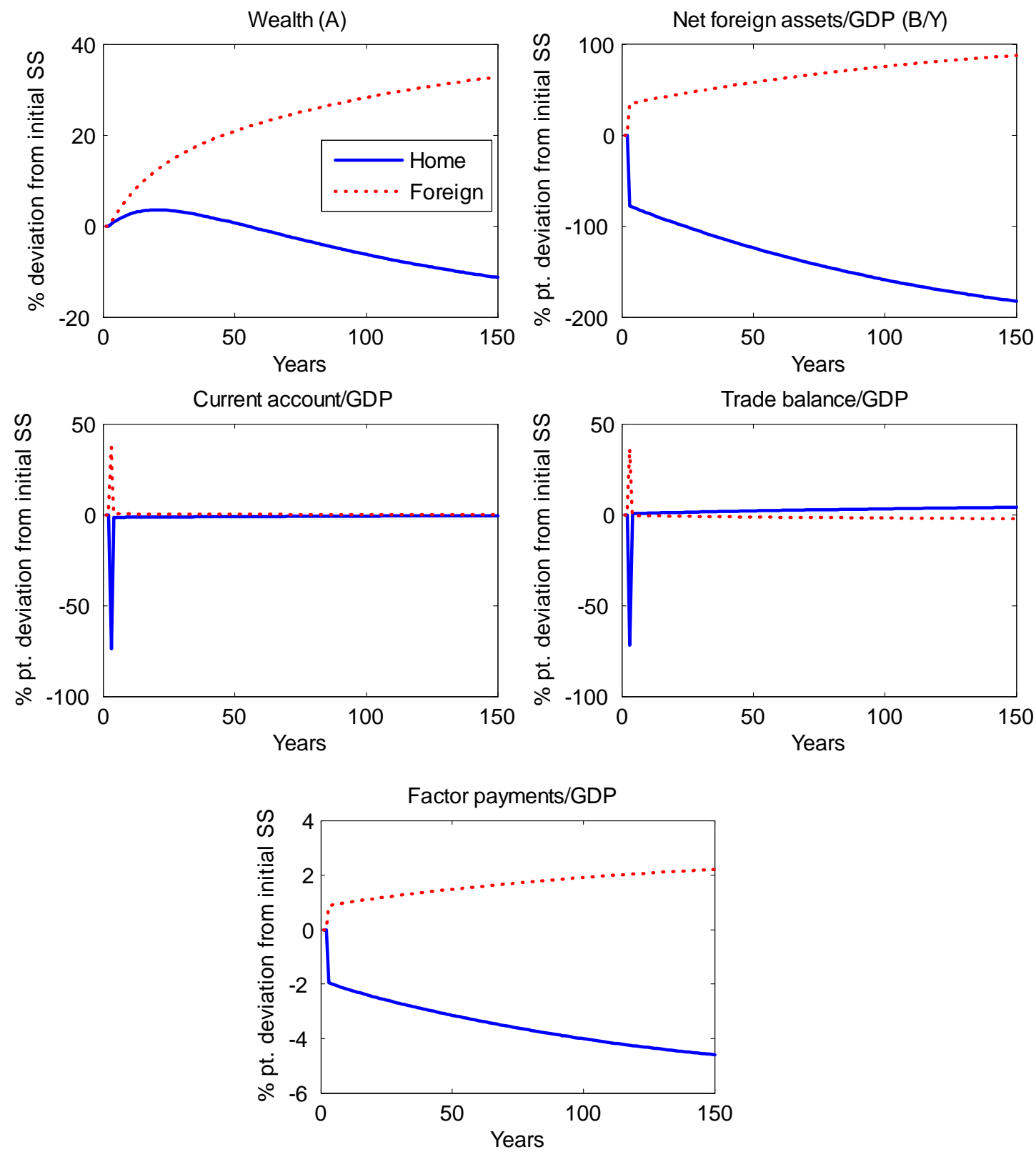

Figure A4b: Dynamics after the elimination of Home capital income tax with taxes on private bonds 

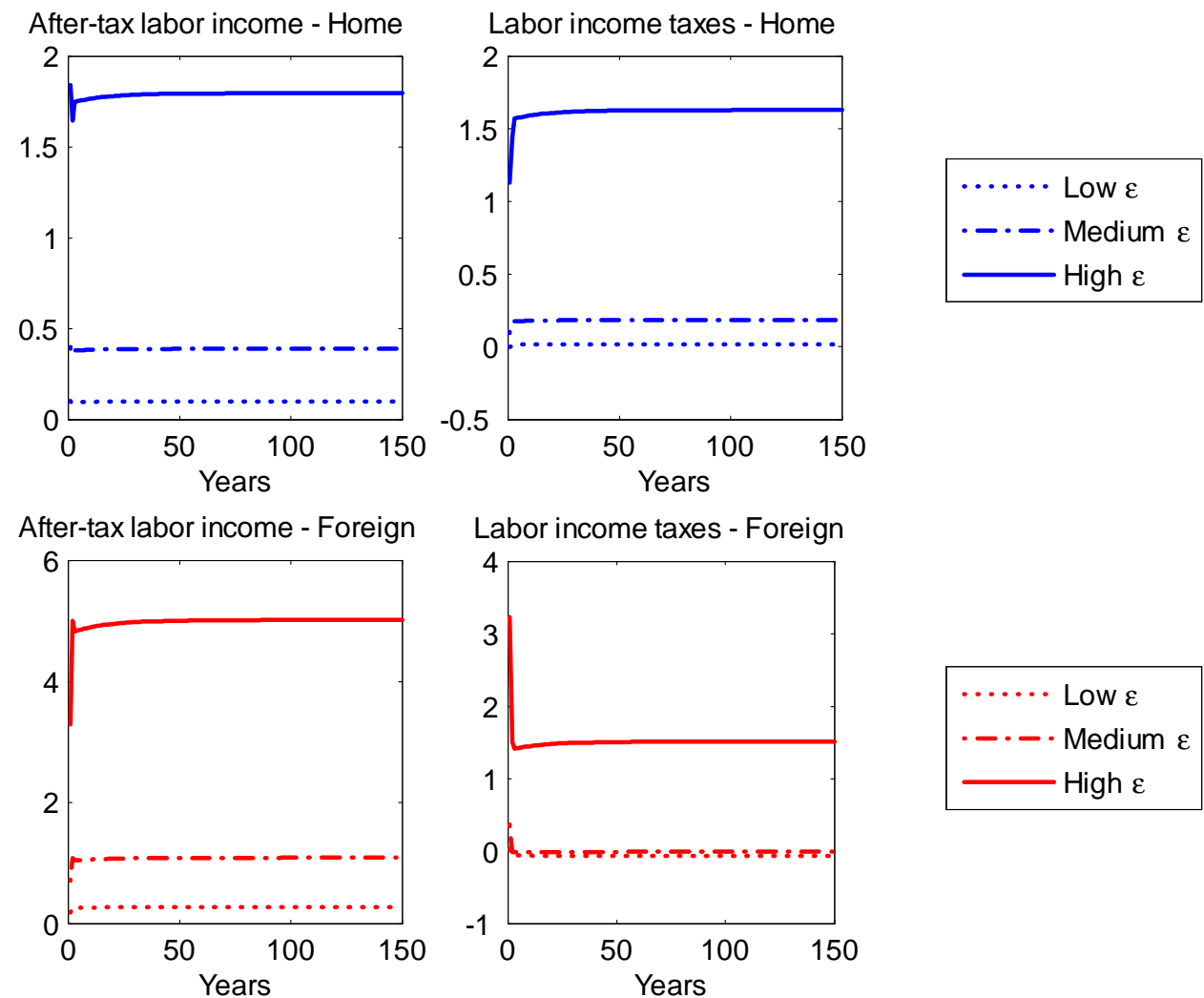

Labor income taxes - Foreign
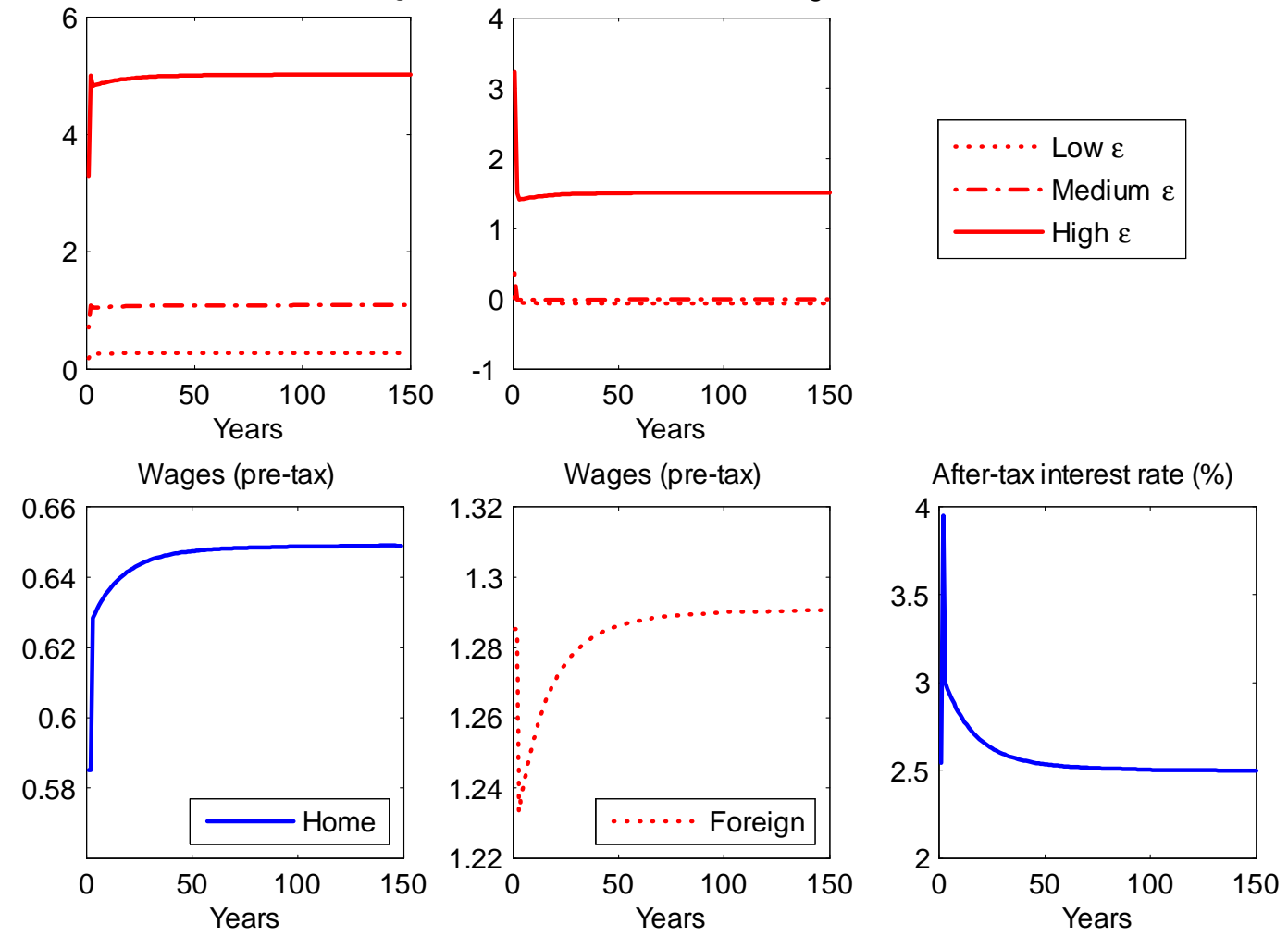

Figure A4c: Dynamics after the elimination of Home capital income tax with taxes on private bonds 